\title{
Morphology of Upper and Lower Bainite with 0.7 Mass Pct C
}

\author{
JIAQING YIN, MATS HILLERT, and ANNIKA BORGENSTAM
}

\begin{abstract}
There has been an on-going discussion on the difference in formation mechanisms of upper and lower bainite. Various suggestions have been supported by reference to observed morphologies and illustrated with idealized sketches of morphologies. In order to obtain a better basis for discussions about the difference in mechanism, the morphology of bainite in an $\mathrm{Fe}-\mathrm{C}$ alloy with 0.7 mass pet carbon was now studied in some detail from $823 \mathrm{~K}$ to $548 \mathrm{~K}\left(550{ }^{\circ} \mathrm{C}\right.$ to $\left.275^{\circ} \mathrm{C}\right)$ at temperature intervals of $50 \mathrm{~K}$ or less. The work focused on bainite seen to start from a grain boundary in the plane of polish and showing an advancing tip in the remaining austenite. The results indicate that there is no essential difference with temperature regarding the ferritic skeleton of feathery bainite. The second stage of bainite formation, which involves the formation of both ferrite and cementite, was regarded as a eutectoid transformation and the resulting morphologies were analyzed in terms of two modes, degenerate and cooperative eutectoid transformation. There was no sharp difference between upper and lower bainite. Ways to define the difference were discussed.
\end{abstract}

DOI: $10.1007 / \mathrm{s} 11661-017-4208-5$

(C) The Author(s) 2017. This article is an open access publication

\section{INTRODUCTION}

MEHL $^{[1]}$ introduced the terms upper and lower bainite. He illustrated upper bainite with micrographs of feathery bainite, which originates from grain boundaries. It is composed of very many parallel plates of ferrite with cementite particles in the interspaces. He illustrated lower bainite with acicular units, initiated by intragranular nucleation of ferrite plates. It seems that Mehl, in reality, simply distinguished between bainite nucleated either at grain boundaries or intragranularly. Hultgren ${ }^{[2]}$ presented a sketch of the start of upper bainite where the plates were nucleated on a grain boundary and somewhat elongated cementite particles formed in the interspaces. Aaronson and Wells ${ }^{[3]}$ introduced the term "sheaf" for intragranular groups of closely packed parallel plates and proposed that they form by repeated sympathetic nucleation, starting from an initial plate of ferrite. Hillert ${ }^{[4]}$ observed that the outermost plate of ferrite in feathery bainite was sometimes covered with a more intimate mixture of ferrite and cementite. It could also form in a wider interspace between ferrite plates. He did not identify it as pearlite but proposed that it was a eutectoid mixture

JIAQING YIN, MATS HILLERT, and ANNIKA BORGENSTAM are with the Department of Materials Science and Engineering, KTH Royal Institute of Technology, Brinellvägen 23, 10044 Stockholm, Sweden. Contact e-mail: jiaqing@kth.se

Manuscript submitted April 12, 2017.

Article published online July 6, 2017 that had formed under cooperation between ferrite and cementite although the ferritic constituent came from the bainitic ferrite. He predicted that this mixture should be more common at lower temperatures. Ko and Cottrell ${ }^{[5]}$ discovered that bainite, similarly to martensite, forms with a surface relief. That inspired Matas and Hehemann ${ }^{[6]}$ to propose that bainitic ferrite grows very fast, without time for diffusion of carbon. Cementite in lower bainite would then form by a subsequent precipitation of carbon from the supersaturated ferrite. At higher temperatures, there would instead be time for carbon to escape to austenite in the interspaces where it would precipitate as coarse particles of cementite. However, they had measured the lengthening rate of bainite ${ }^{[7]}$ and Kaufman, Radcliffe and Cohen ${ }^{[8]}$ reported that their and similar growth rates ${ }^{[9,10]}$ were slow enough to be accounted for by carbon diffusion during growth. Goodenow and Hehemann ${ }^{[11]}$ then explained this apparent discrepancy by proposing that the lengthening of a bainite unit occurs by rapid, diffusionless formation of subunits of limited length and the slower macroscopic growth rate is controlled by slow nucleation of a succession of subunits. Oblak and Hehemann ${ }^{[12]}$ published micrographs of subunits and a sketch illustrating the morphological differences of Widmanstätten ferrite, upper bainite, and lower bainite. The proposal by Matas and Hehemann, ${ }^{[6]}$ that cementite precipitates from austenite in upper bainite and from supersaturated ferrite in lower bainite, is still widely accepted as the basis for defining and explaining the morphological difference between upper and lower bainite. A mixture 
of the two morphologies of cementite can often be observed, and it has been illustrated in sketches, e.g., by Ohmori et al. ${ }^{[13]}$ and Takahashi and Bhadeshia. ${ }^{\left[{ }^{4}\right]}$ On the other hand, Ohmori et al., ${ }^{[13]}$ who also discussed the morphological differences of upper and lower bainite, proposed that the morphological differences in the ferritic constituent should be considered, i.e., upper bainite consists of lath-shaped ferrite whereas lower bainite consists of plate-shaped ferrite. The definitions for upper and lower bainite will be considered in the discussion. Until then, upper and lower bainite will stand for bainite from higher and lower temperature ranges.

A recent study of the morphology of bainite formation in some $\mathrm{Fe}-\mathrm{C}$ steels with 0.3 mass pct carbon resulted in two papers. The first one ${ }^{[15]}$ reported on the effect of grain boundaries on the proeutectoid formation of ferrite. There was a large variation in shape of ferrite particles soon after nucleation but it was observed that their shapes were very similar for each grain boundary. Usually, there was just one kind of shape at a boundary but sometimes two and even more. It was concluded that the large variation of shape, observed between various grain boundaries, was related to the presumed large variation of their crystallographic structure, which is controlled by the relative orientation of the two grains and the direction of the grain boundary relative to the two lattices. Many shapes had facets to both grains of austenite, and a particularly interesting shape was called chevron because it consisted of two legs, one in each austenite grain. Given more time, the legs of a chevron will develop plates and a long series of chevron particles, often covering the whole length of a grain boundary, will develop into a feathery microstructure composed of parallel plates of ferrite in each grain. Sometimes the arrangement of closely spaced, parallel plates only occurred on one side of the grain boundary and they were called semi-feathers. It was concluded that they were formed from other shapes of ferrite particles.

In that work it was realized that, in order to study how the microstructure of bainite develops during growth, it was essential to study a section containing the main growth direction of an object. To increase the chance of finding objects, sectioned in this way, it was decided to study objects starting their growth from a grain boundary. It was then found that one could often observe cases where a plate of ferrite could be followed all the way from start to growth front without any interruption. It was concluded that the lengthening of bainitic ferrite does not depend on repeated nucleation and rapid growth of subunits to a limited length as suggested by Goodenow and Hehemann ${ }^{[11]}$ and still widely accepted. ${ }^{[16]}$ The same alloys with 0.3 mass pct carbon were used in the second part of the recent study, ${ }^{[17]}$ which focused on the second stage of upper bainite formation, in which the thin interspaces between the ferrite plates transform, triggered by the occurrence of cementite. It was stated that chemically this is a eutectoid reaction because cementite stimulates the simultaneous growth of ferrite, although the eutectoid transformation mostly degenerates in upper bainite.
The elongated cementite particles, typical of upper bainite, were predominant in the whole experimental range of temperature but small colonies, typical of lower bainite, appeared in the lower part of the range. This confirmed the observation by Hillert, ${ }^{[4]}$ who concluded that the eutectoid transformation in the second stage of bainite formation can occur in two modes, a cooperative or degenerate eutectoid reaction. He further speculated that the cooperative eutectoid would be more common at even lower temperatures. In the study of alloys with 0.3 mass pct carbon, an attempt was made to examine how such a transition to lower bainite could occur but the experimental range was limited by the high $\mathrm{M}_{\mathrm{S}}$ temperature. The present study was undertaken partly in order to extend the experimental range by depressing the $\mathrm{M}_{\mathrm{S}}$ temperature through an increase of the carbon content to 0.7 mass pct carbon. Due to the importance of studying units sectioned along their full length, the main attention was again paid to objects starting from grain boundaries in the plane of polish.

\section{EXPERIMENTAL DETAILS}

A high purity $\mathrm{Fe}-\mathrm{C}$ alloy was applied in present work, its chemical composition and the calculated martensite start $\left(M_{\mathrm{s}}\right)$ temperature ${ }^{[18]}$ are given in Table I. A carbon content of 0.7 mass pct was chosen to depress the $M_{\mathrm{s}}$ temperature to some extent and with a hope that at lower temperatures bainite would develop without competition from martensite as with the 0.3 mass pct $\mathrm{C}$ alloy applied in preceding work. ${ }^{[17]}$ The material was first hot rolled to $3.6 \mathrm{~mm}$, and after removing the decarburized layers on both sides, it was cold rolled to a thickness of $1.5 \mathrm{~mm}$. Specimens, in size of roughly $7 \times 6$ $\mathrm{mm}$, were austenitized at $1373 \mathrm{~K}\left(1100{ }^{\circ} \mathrm{C}\right)$ for 10 minutes under protective argon atmosphere and then manually transferred to a Bi-Sn melt. After isothermal holding, the specimens were quenched in iced brine. Isothermal treatment was carried out over a temperature range from $973 \mathrm{~K}$ to $523 \mathrm{~K}\left(700{ }^{\circ} \mathrm{C}\right.$ to $\left.250{ }^{\circ} \mathrm{C}\right)$ in a $50 \mathrm{~K}$ interval with an additional temperature of $548 \mathrm{~K}$ $\left(275^{\circ} \mathrm{C}\right)$. All specimens were mechanically polished ending with $0.02 \mu \mathrm{m}$ silica.

The specimens were initially examined with light optical microscopy (LOM) and 2 mass pet picral was applied to reveal the microstructure. At high magnification, transmission electron microscopy (TEM) has usually been the main tool to study the morphology of lower bainite to obtain morphological and crystallographic information. However, some disadvantages are obvious. The preparation of TEM samples is destructive and the observation area is limited to an area of roughly $100 \times 100 \mu \mathrm{m}^{2}{ }^{[19]}$ These disadvantages prevent efforts to link the high-magnification information obtained in TEM with the low-magnification information from the same position. Such information was critical since in the preceding work ${ }^{[15]}$ it was demonstrated that the interpretation of 3D morphology, based on $2 \mathrm{D}$ pictures, is easily influenced by an effect of sectioning and the direction of the plane of polish, relative to the bainite 
Table I. Chemical Composition (Mass Pct) of Alloy, the Martensite Start $\left(M_{\mathrm{s}}\right)$ Temperature Is Calculated with the Model of Stormvinter et al. ${ }^{[18]}$

\begin{tabular}{lccccccc}
\hline $\mathrm{C}$ & $\mathrm{Si}$ & $\mathrm{Mn}$ & $\mathrm{P}$ & $\mathrm{S}$ & $\mathrm{B}$ & Others & $M_{\mathrm{s}}\left[\mathrm{K}\left({ }^{\circ} \mathrm{C}\right)\right]$ \\
\hline 0.699 & 0.033 & 0.003 & 0.001 & $<0.001$ & $<0.0003$ & $<0.025$ & $539(266)$ \\
\hline
\end{tabular}

unit, is more evident at low magnification. It was thus decided to apply scanning electron microscopy (SEM) as the main tool. In general, SEM is particularly useful for studying 3-D features after deep etching and for very fine microstructures even ordinary etching may give the impression of deep etching. The electron channeling contrast imaging (ECCI) technique requires polished surfaces, which is thus an advantage in the study of fine microstructures.

ECCI and electron backscatter diffraction (EBSD) were applied for special purposes. They are both applied to specimens in polished condition and can be applied directly after each other on the same area. Theory and application of the ECCI technique were recently reviewed. ${ }^{[20,21]}$ In contrast to the ordinary SEM, it uses signals of backscattered electrons which are influenced by material composition, crystal orientation, and topography of the sample surface. ${ }^{[22]}$ ECCI is also influenced by the lattice orientation relative to the primary beam. Minimum backscatter is expected when the beam fulfills exactly the Bragg condition to the lattice planes. In order to obtain the best contrast, it is thus necessary to manipulate the beam in combination with sample tilt. A traditional method for doing this was first proposed by Morin et $a l^{[23]}$ In order to simplify the operation, Zaefferer ${ }^{[24,25]}$ proposed a new method to replace the "rocking beam" method with a combination of EBSD technique and simulation of "electron channelling pattern" (ECP) for sample under different tilt angles. The application of ECCI technique in the present work is rather primitive and no sample tilt was applied through the work. Without tilt operation though, it was found that it can give sufficient contrast between ferrite and cementite as illustrated by Figure 1 of pearlite behind the interface between a pearlite nodule and austenite/martensite. The ferrite phase is shown with different shades, supposedly due to slight differences in orientation between separate sub-colonies that seem to develop continuously during growth. It is interesting that cementite appears bright when ferrite is dark and vice versa. Possibly due to less skillful preparation of specimens in the present work, white clouds could occur erratically. An effort was made to avoid them but they appear sometimes in the micrographs.

The ordinary SEM and ECCI work was carried out with a field emission gun-scanning electron microscope (FEG-SEM) JEOL JSM-7800F (Japan Electron Optics Laboratory Ltd., Tokyo, Japan), operating at 10 to 15 $\mathrm{kV}$ with a working distance of $7 \mathrm{~mm}$. The same electron microscope was used for EBSD study, an accelerating voltage of $15 \mathrm{kV}$ and a step size of $50 \mathrm{~nm}$ were applied. The EBSD data were processed with QUANTAX CrystAlign software. The resolution of these techniques is usually better than evident from the printed copies.

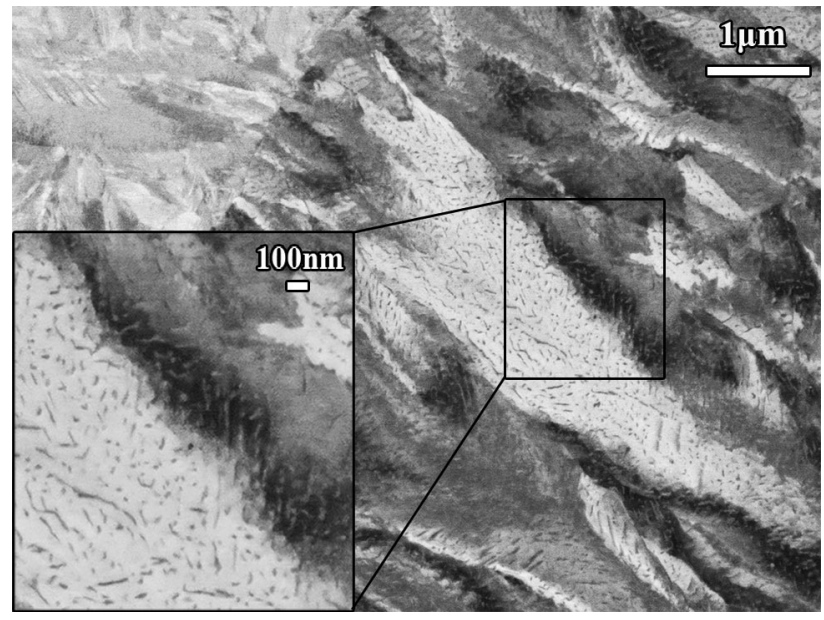

Fig. 1-Pearlite colonies with ECCI. The contrast of ferrite and cementite varies with the change of crystallographic orientation. From $773 \mathrm{~K}\left(500{ }^{\circ} \mathrm{C}\right)$ held for $8 \mathrm{~s}$.

Higher resolution is offered through the on-line version which should be consulted when needed.

In view of the prior experience, most of the microscopic observations were made on objects showing their starting points on some grain boundary and with an emphasis on objects that seemed to be sectioned close to their main growth direction. Well-developed feathery bainite covering a grain boundary as well as more dispersed parallel packets were examined. Cross sections through packets were examined for special purposes. The isothermal holding times were sufficiently short to prevent unnecessarily complicated microstructures when the degree of transformation is increasing.

\section{OBSERVATIONS OF SHAPES}

A preliminary survey was made with LOM. At $973 \mathrm{~K}$ $\left(700{ }^{\circ} \mathrm{C}\right)$ the transformation from an austenitic state started with ferrite precipitation as expected for 0.7 mass pct carbon, which is slightly hypoeutectoid. Grain boundary films were formed but also more compact particles, e.g., of the so-called chevron type with one leg in each grain, Figure 2(a). In the preceding study of the morphology of ferrite, ${ }^{[15]}$ it was found that they play an important role in the formation of feathery bainite. It is here illustrated how their further development was stopped by pearlite. Pearlite predominates even more at $923 \mathrm{~K}$ and $873 \mathrm{~K}\left(650{ }^{\circ} \mathrm{C}\right.$ and $\left.600{ }^{\circ} \mathrm{C}\right)$. Figure 2(b) demonstrates that some grain boundaries did not nucleate pearlite but stimulated the formation of an acicular constituent. The two pearlite nodules seen on the sides were nucleated at grain edges. Such grain 
boundaries were found already in the preceding work on proeutectoid ferrite, and it was suggested that they are special boundaries, which stimulate only the nucleation of ferrite with such orientation relationships to the two austenite grains that they cannot develop into pearlite. At this temperature, pearlite would otherwise predominate due to its higher growth rate. At $773 \mathrm{~K}\left(500{ }^{\circ} \mathrm{C}\right)$, pearlite no longer predominates and Figure 2(c) illustrates that an acicular constituent can grow ahead of a nodule that was nucleated at the same grain boundary.

The competition from pearlite was negligible at $723 \mathrm{~K}$ $\left(450{ }^{\circ} \mathrm{C}\right)$. Figures $3(\mathrm{a})$ and (b) show small units of bainite after 5 seconds. It is evident that the chevron shape in (a) contains a number of ferrite chevrons packed very closely. It thus represents an early stage of feathery bainite composed of one packet of ferrite plates in each grain. In Figure 3(b), there is a family of parallel packets of plates growing into one grain and there are some short outgrowths into the other grain. Their nature is uncertain but it is feasible that they are close groups of plates growing with a large angle to the plane of polish. Figure 4(a) illustrates a further development after 8 seconds. This object consists of packets separated by rather wide interspaces. It could rather be compared with a fishbone than a feather but will here be regarded as an incomplete feather. It has one family of packets on the upper side and two families on the lower side. Figure 4(b) illustrates that there is a tendency to form complete feathers also at $723 \mathrm{~K}\left(450{ }^{\circ} \mathrm{C}\right)$.

Figures 5(a) and (b) demonstrate that groups of chevrons can also form at $673 \mathrm{~K}\left(400{ }^{\circ} \mathrm{C}\right)$ and after longer times they would develop in the feathery fashion. It should be noted that each chevron probably consists of several, very closely packed chevrons of ferrite. When developed under longer time they would probably have yielded families of packets of plates with wide interspaces, i.e., an incomplete feather.

After 40 seconds at $623 \mathrm{~K}\left(350{ }^{\circ} \mathrm{C}\right)$, there was intragranular nucleation of acicular bainite, Figure 6, but feathers could still develop. The microstructure is too complex to allow chevrons to be distinguished but a few may be identified in the left-hand part. $30 \mathrm{sec}-$ onds at $573 \mathrm{~K}\left(300{ }^{\circ} \mathrm{C}\right)$ was too short to give more than a few intragranular units of bainite but a long series of chevrons could be observed, Figure 7. After 60 seconds feathers had developed, Figure 8. At $548 \mathrm{~K}$ $\left(275^{\circ} \mathrm{C}\right)$, a few units of martensite were observed but were difficult to distinguish from bainite in LOM. At $523 \mathrm{~K}\left(250^{\circ} \mathrm{C}\right)$, there was a large fraction of martensite.

In the preceding study of proeutectoid ferrite, ${ }^{[15]}$ it was concluded that feathery bainite can develop from grain boundaries with a series of ferrite particles shaped as chevrons. It is thus interesting that both features, chevrons and more or less complete feathers, were now observed in the whole range of temperature; examples at $573 \mathrm{~K}\left(300{ }^{\circ} \mathrm{C}\right)$ are shown in Figures 7 and 8. In the whole range, there was a variety of feathery structures from more or less complete feathers or semi-feathers to incomplete feathers and more dispersed parallel packets. No general difference in shape between grain boundary nucleated bainite formed in the temperature region studied was found.

\section{OBSERVATIONS OF THE INNER STRUCTURE}

\section{A. At $823 \mathrm{~K}\left(550^{\circ} \mathrm{C}\right)$}

The internal structure of pearlite at $823 \mathrm{~K}\left(550{ }^{\circ} \mathrm{C}\right)$ was very similar to that of pearlite in Figure 1 from 773 $\mathrm{K}\left(500{ }^{\circ} \mathrm{C}\right)$, and it may be noted that it is only partially lamellar although the carbon content, 0.7 mass pet, was not far from the eutectoid. The remaining part is fibrous. The 3-D morphology is shown by SEM in Figure 9 and the fibers predominate.

It was possible to study other microstructures than pearlite at $823 \mathrm{~K}\left(550^{\circ} \mathrm{C}\right)$ although pearlite still predominated. Figure 10(a) shows a special grain boundary without pearlite. It shows two different kinds of feathers. One has been attacked by etching more than the other but both have been attacked in the same way on both sides of the grain boundary. Moreover, each one has the same extension along the grain boundary on both sides. It may also be noted that the left-hand object finishes with a sharp tip on the grain boundary, and one may imagine that it is the angle of a chevron. Furthermore, the EBSD micrograph in Figure 10(b) shows that for each object the ferritic constituent on both sides of the prior grain boundary has the same crystalline orientation. These features strongly indicate that the ferritic constituents of these objects are of the same kind as for feathery bainite. Nevertheless, one could hesitate to define them as feathery bainite because the object with less attack by etching does not show any sharp tips of ferrite on any side and the other object, which has sharp tips, often has a central plate of cementite in the tip as shown at high magnification in Figure 11. This is supported by a similar object in Figure 12 .

\section{B. At $773 \mathrm{~K}\left(500{ }^{\circ} \mathrm{C}\right)$}

Pearlite still forms as nodules at $773 \mathrm{~K}\left(500{ }^{\circ} \mathrm{C}\right)$ and Figure 1 already illustrates the growth front of pearlite to austenite/martensite. Three acicular objects have competed successfully with pearlite in Figure 13(a). For some reason, the surface conditions of the middle object have had a bad effect on the ECCI technique and the internal structure cannot be seen. They all originated at a grain boundary and so did the nodule of pearlite. An upper part of one of the packets is magnified in Figure 13(b). In this case, the plates are spaced rather regularly except for the gap in the middle.

It may be tempting to regard Figure 14 as part of feathery bainite because most of it is acicular ferrite and cementite. However, most of the interspaces are rather wide and at higher magnification in Figure 15(a) it was revealed that they are filled with a eutectoid mixture which was recognized as pearlite. The arrow in Figure 15(b) shows how a colony of this eutectoid mixture is in the process of covering the side of a ferrite plate. It is evident that the plates formed first and that 

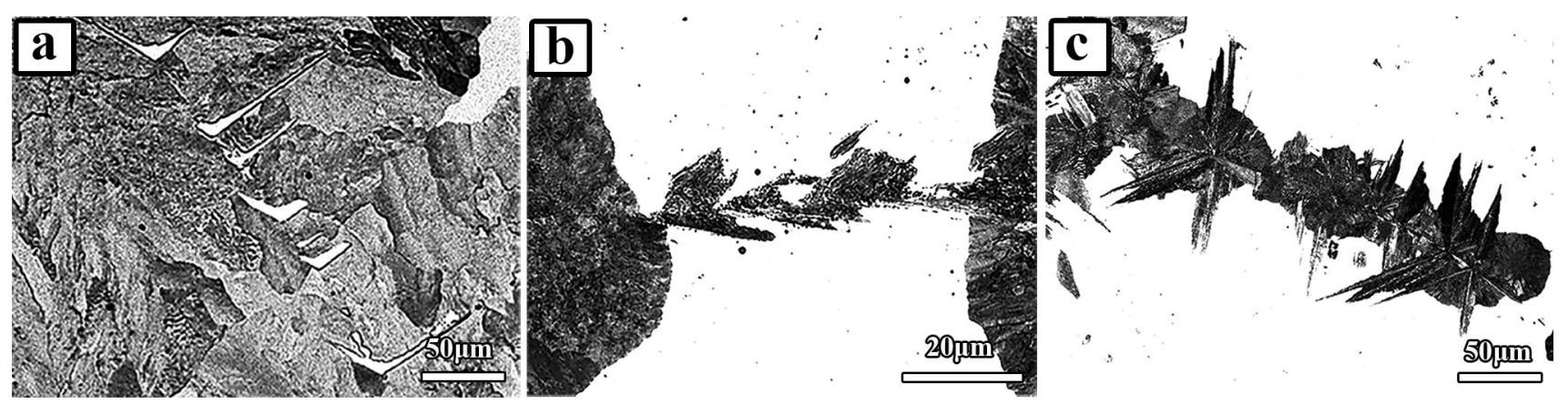

Fig. 2 - Chevron structure observed with LOM, as individual plate in (a) and packet of plates in (b) and (c). (a) From $973 \mathrm{~K}\left(700{ }^{\circ} \mathrm{C}\right)$ held for 3 min, (b) from $823 \mathrm{~K}\left(550^{\circ} \mathrm{C}\right)$ held for $2 \mathrm{~s}$, and (c) from $773 \mathrm{~K}\left(500{ }^{\circ} \mathrm{C}\right)$ held for $10 \mathrm{~s}$.

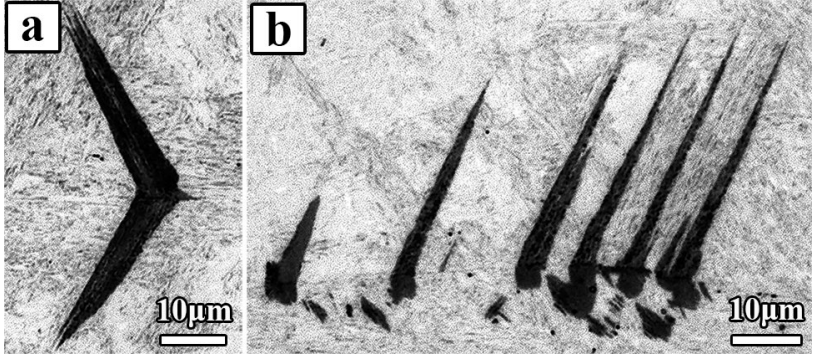

Fig. 3-Chevron packets observed with LOM, (a) with almost symmetric two legs and $(b)$ with one leg more developed than another, both from $723 \mathrm{~K}\left(450^{\circ} \mathrm{C}\right)$ held for $5 \mathrm{~s}$.

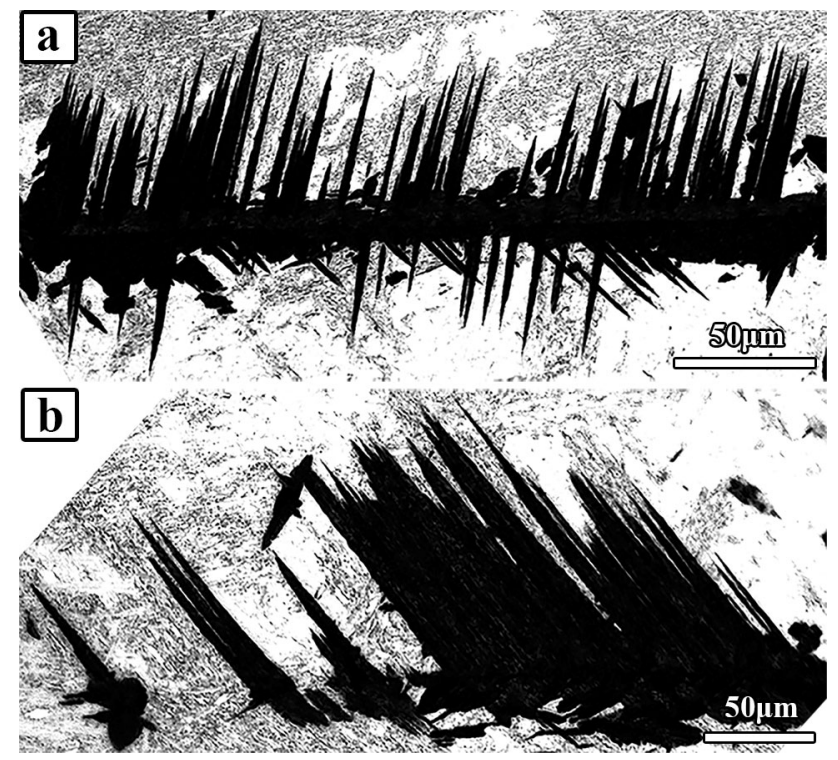

Fig. 4 - Chevron packets observed with LOM, (a) separated packets resembling an incomplete feather, and $(b)$ the term of "complete feather" might be applied if the grain boundary is covered fully by dense packets as seen on the right side, both from $723 \mathrm{~K}\left(450^{\circ} \mathrm{C}\right)$ held for $8 \mathrm{~s}$.

the growth rate of the eutectoid is highest along the broad face of ferrite. Only the ferritic constituent of bainite looks black in the ECCI micrographs of Figures 13, 14, and 15, which shows that the lattice orientations of martensite and pearlitic ferrite are different. The orientation difference to the latter was

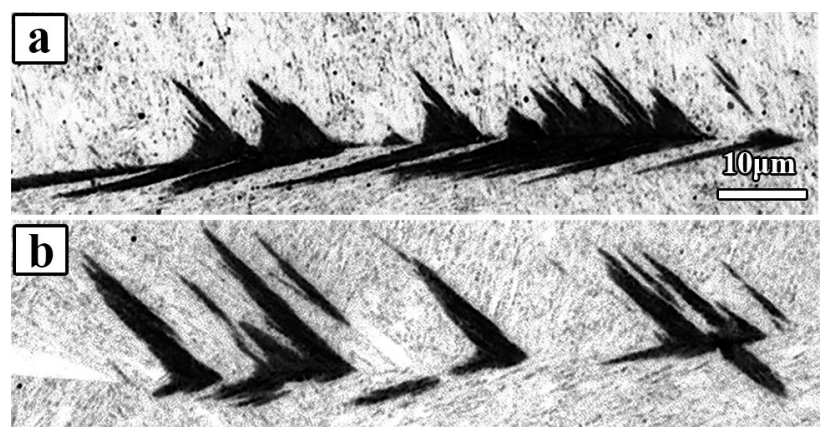

Fig. 5-Chevron packets observed with LOM, (a) from $673 \mathrm{~K}$ $\left(400{ }^{\circ} \mathrm{C}\right)$ held for $5 \mathrm{~s}$ and $(b)$ from $673 \mathrm{~K}\left(400{ }^{\circ} \mathrm{C}\right)$ held for $10 \mathrm{~s}$.

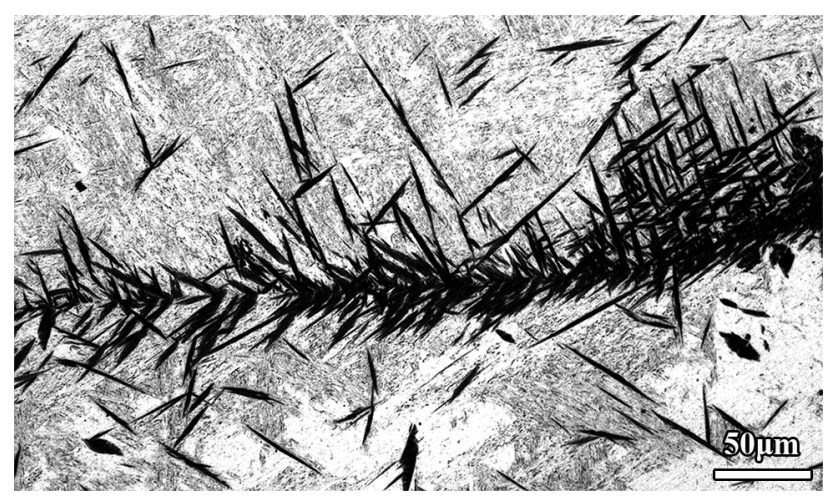

Fig. 6 - Chevron packets observed with LOM, intragranular packets are seen in the interior of the prior austenite grains, from $623 \mathrm{~K}$ $\left(350{ }^{\circ} \mathrm{C}\right)$ held for $40 \mathrm{~s}$.

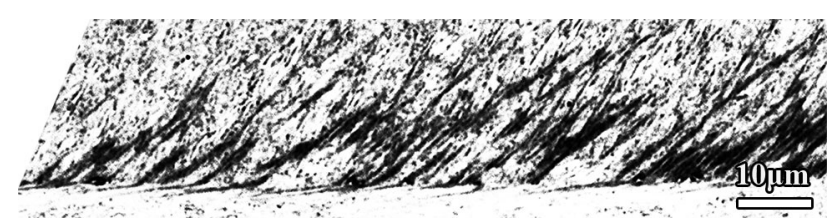

Fig. 7-Chevron packets from early stage of transformation, observed with LOM. The lower legs are almost parallel to the grain boundary, from $573 \mathrm{~K}\left(300^{\circ} \mathrm{C}\right)$ held for $30 \mathrm{~s}$.

explored through the EBSD micrograph in Figure 16 where the arrow is from the same position as the arrow in Figure 15(b). The accompanying misorientation map 


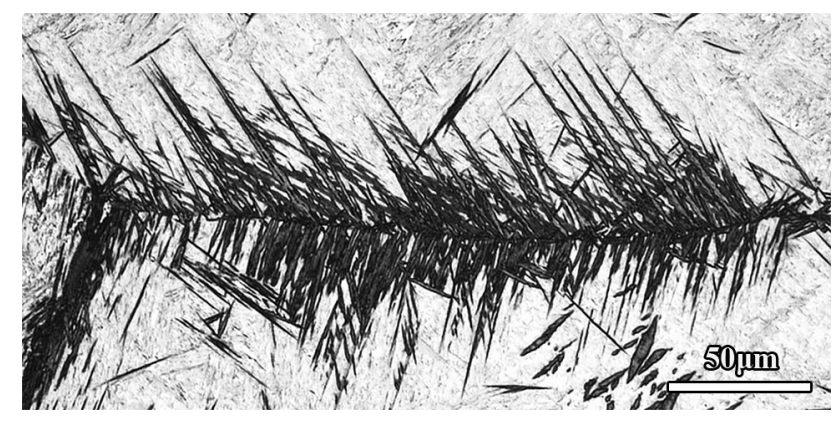

Fig. 8- Chevron packets from later stage of transformation, observed with LOM. Several other groups of packets are present. From $573 \mathrm{~K}\left(300{ }^{\circ} \mathrm{C}\right)$ held for $60 \mathrm{~s}$.

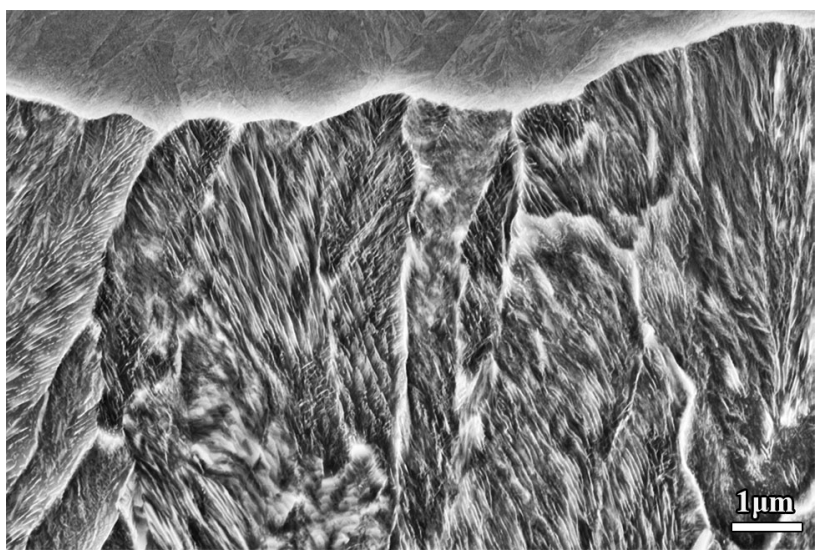

Fig. 9-Pearlite morphology with SEM, deep etching is applied, cementite is mostly fibrous, from $823 \mathrm{~K}\left(550{ }^{\circ} \mathrm{C}\right)$ held for $2 \mathrm{~s}$.
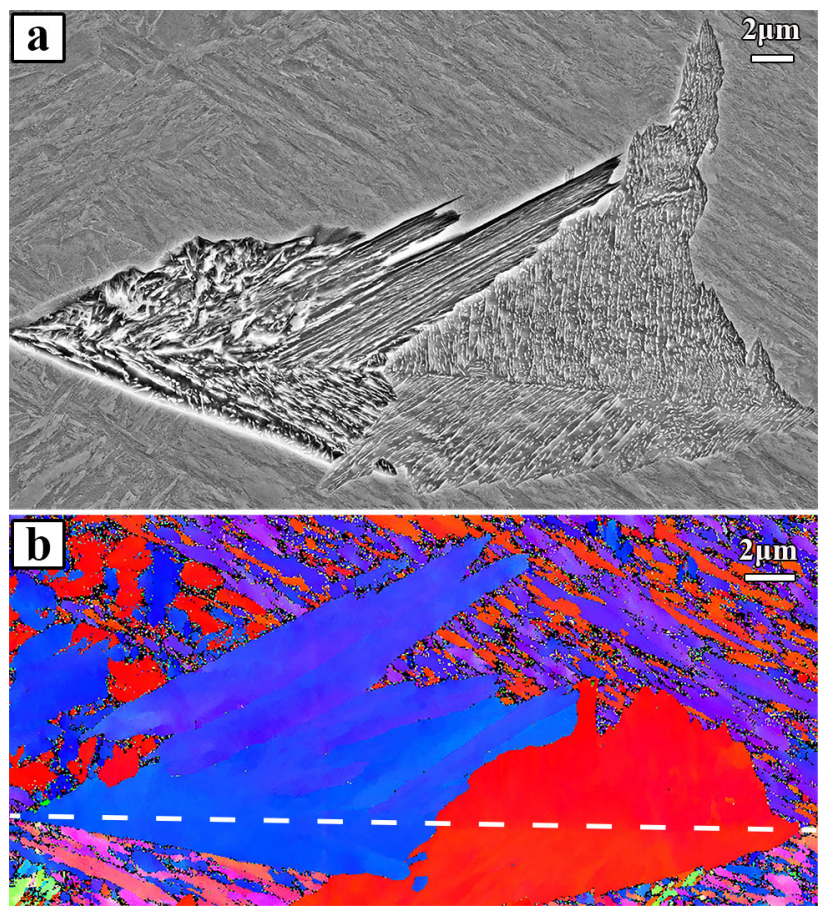

Fig. 10-Two packets observed with (a) SEM and (b) EBSD IPF map after a new polish. From $823 \mathrm{~K}\left(550^{\circ} \mathrm{C}\right)$ held for $2 \mathrm{~s}$.

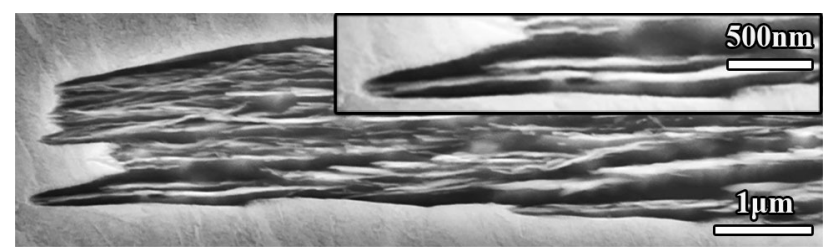

Fig. 11-Higher magnification of packet from Fig. 10 with SEM. Cementite lamella is seen close to the very tip. From $823 \mathrm{~K}\left(550{ }^{\circ} \mathrm{C}\right)$ held for $2 \mathrm{~s}$.

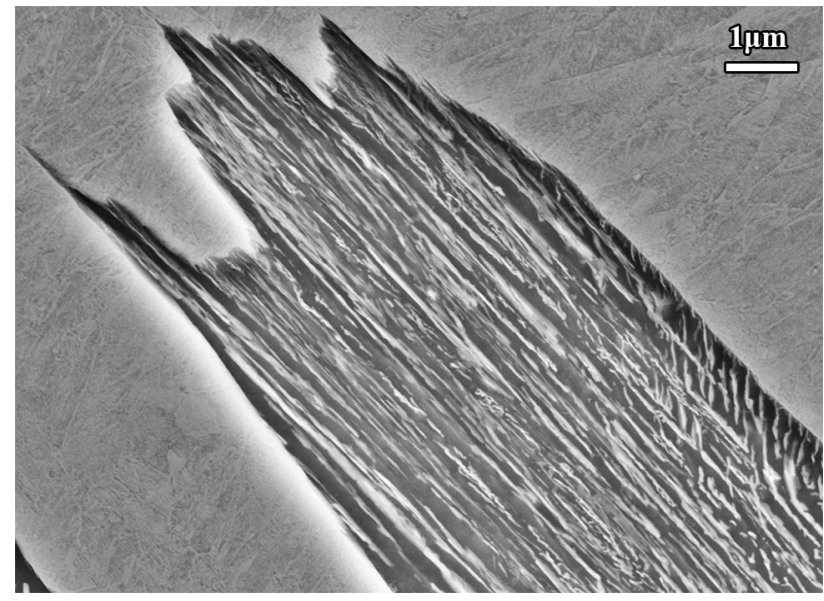

Fig. 12-Similar structure as in Fig. 11. From $823 \mathrm{~K}\left(550^{\circ} \mathrm{C}\right)$ held for $2 \mathrm{~s}$.

shows an orientation difference of about $6 \mathrm{deg}$. It is known that bainitic ferrite has an orientation relationship to the parent austenite that is not favorable for cooperation with cementite to form pearlite. ${ }^{[26]}$ It is here evident that a difference of $6 \mathrm{deg}$ was sufficient for making it possible. One may speculate that this ferrite originated from the acicular ferrite by a gradual rotation during growth somewhere, rather than by random nucleation. Figure 17 shows spears with a centerline of very few ferrite plates, surrounded by layers, which were identified as pearlite due to its similarity with the pearlitic nodule to the lower left corner.

Figure 18 from 10 seconds at $773 \mathrm{~K}\left(500{ }^{\circ} \mathrm{C}\right)$ shows the inner structure of a wide packet of ferrite plates with many of the interspaces transformed by the occurrence of cementite. However, there are still some white lines that may represent austenite.

\section{At $723 \mathrm{~K}\left(450^{\circ} \mathrm{C}\right)$}

Pearlite did not seem to play a major role below $773 \mathrm{~K}$ $\left(500{ }^{\circ} \mathrm{C}\right)$. Figure 19 (a) from $723 \mathrm{~K}\left(450{ }^{\circ} \mathrm{C}\right)$ shows feathery bainite. The EBSD micrograph in Figure 20 and the accompanying misorientation map tell that there is an orientation difference between the ferritic constituent on the two sides of the prior grain boundary but only about $3 \mathrm{deg}$. This supports the previous conclusion $^{[15]}$ that a feather originates from a long series of nuclei that first developed as chevrons but it seems that this ferrite crystal has some ability to adjust 


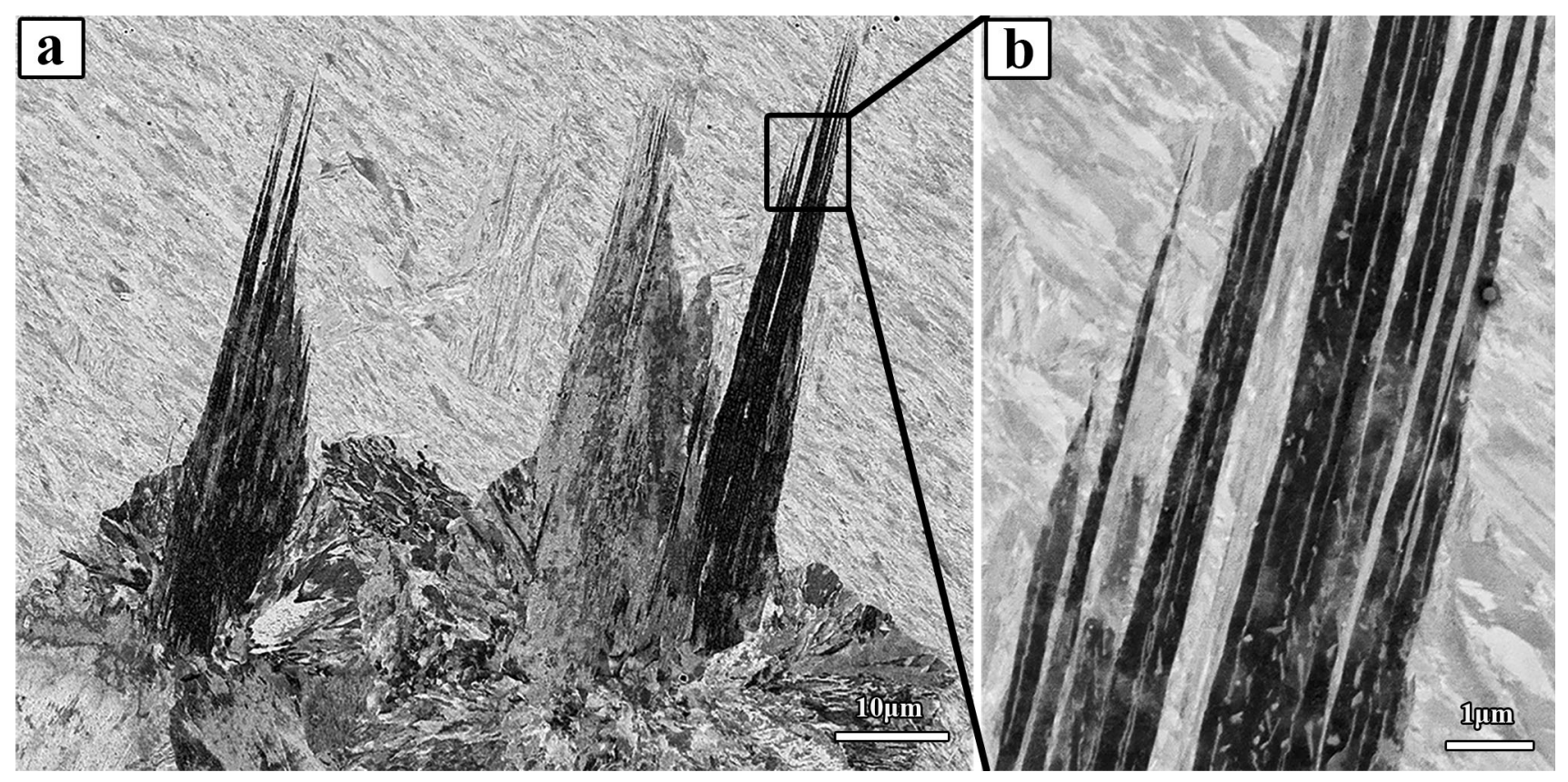

Fig. 13-(a) Bainite packets formed in competition with pearlite nodules, observed with ECCI. (b) Magnified part of the packet in (a), revealing that the austenite bands between primary ferrite plates are being transformed to a mixture of ferrite and cementite. From $773 \mathrm{~K}\left(500{ }^{\circ} \mathrm{C}\right)$ held for $5 \mathrm{~s}$.

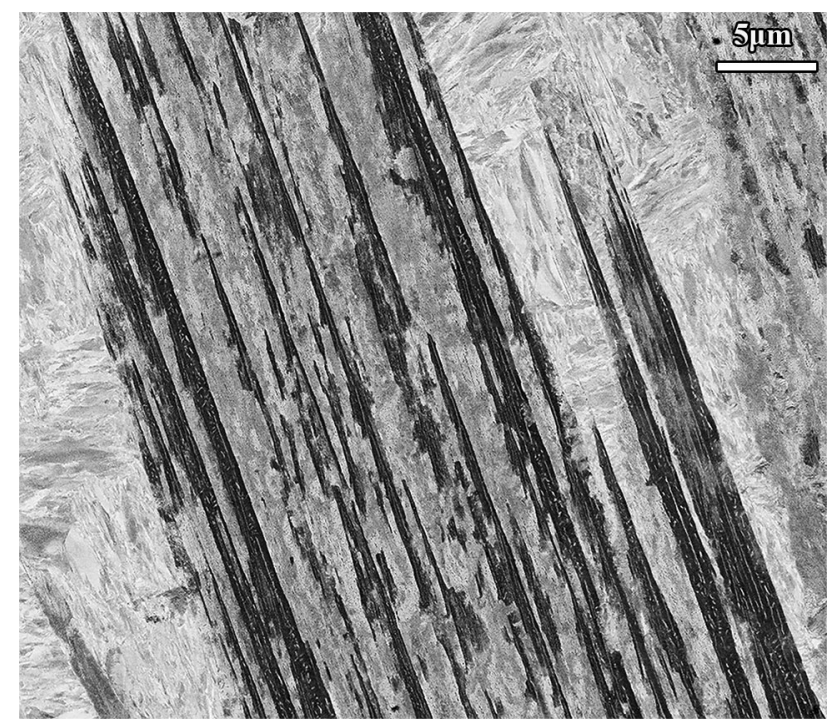

Fig. 14 - Bainite packets, separated by another kind of structure (gray) which also differs from the austenite/martensite matrix (light gray). Observed with ECCI. From $773 \mathrm{~K}\left(500^{\circ} \mathrm{C}\right)$ held for $10 \mathrm{~s}$.

its crystalline orientation to better suit the conditions for growth into the matrix austenite.

The long and thick spear in the left-hand part of Figure 19(a) contains two thin plates that have direct contact with the austenite at the growth front. In the left-hand part of Figure 19(b), which is a magnification of this spear, it can be seen that the plates were covered by thick, speckled layers but according to the EBSD micrograph in Figure 20 they are mainly composed of ferrite of the same crystalline orientation as the plates. Possibly, there may be one or two more plates here and together they may be regarded as a prior packet. The unit to the right in Figure 19(b) has several plates in contact with the austenite at the growth front in Figure 19(a) and they are not packed as closely. It is a matter of definition if such a collection of plates should be regarded as a packet. In Figure 19(b), it seems that their interspaces have been transformed to the same speckled microstructure. Unfortunately, the present etching did not bring out its internal structure. Figure 21 is from a different feather in the same specimen and it demonstrates that the etching has served well to make very elongated cementite particles, or possibly carbon rich austenite, visible as white lines. They show the positions of prior interspaces. By chance, the etching has acted differently at the arrow and brought out the internal structure of the side layer, looking as a cooperative eutectoid.

Close to the center in Figure 21, there is a wide interspace that is being transformed by side-layers, which meet further down. It is interesting that in the fully transformed interspace there is no sign of its position, contrary to the presence of long cementite particles in the position of prior interspaces that were thin. The explanation is that thin interspaces transform by a degenerate eutectoid transformation and wide interspaces transform by a cooperative eutectoid transformation.

In order to study the side layers better, the effect of etching was removed by polishing and the top of the same feather was first examined at higher magnification with ECCI. In Figure 22(a), the contrasts were reversed to make the cementite particles more visible. The different shades from white to gray are probably caused by different surface conditions after polishing. A slightly gray side layer with cooperative eutectoid is shown at 

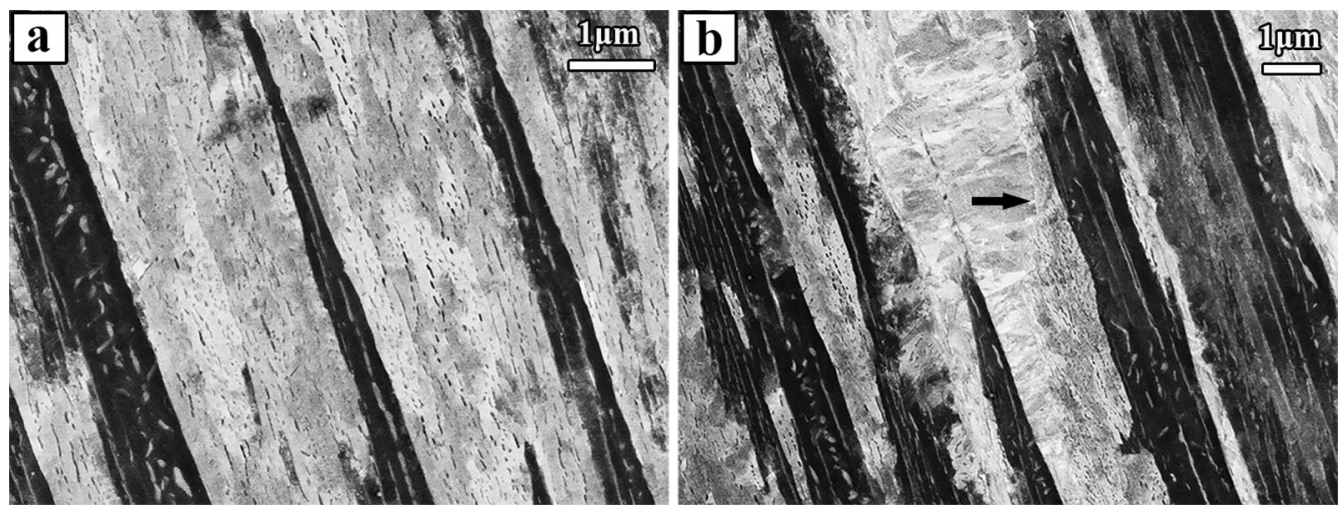

Fig. 15- Higher magnification of two regions from Fig. 14, revealing that interspaces between the bainite packets have transformed into pearlitic structures. The arrow in $(b)$ marks the pearlite/austenite interface.
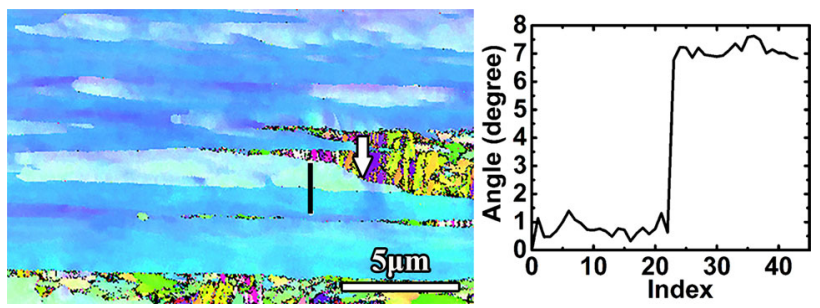

Fig. 16-EBSD IPF map of region shown in Fig. 15(b). A misorientation line scan analysis across pearlite and bainite interface shows that there is about 6 degree rotation for the ferrite lattice. The black line gives the position of the line scan starting from the up side. The white arrow marks the same interface as the arrow in Fig. 15(b).

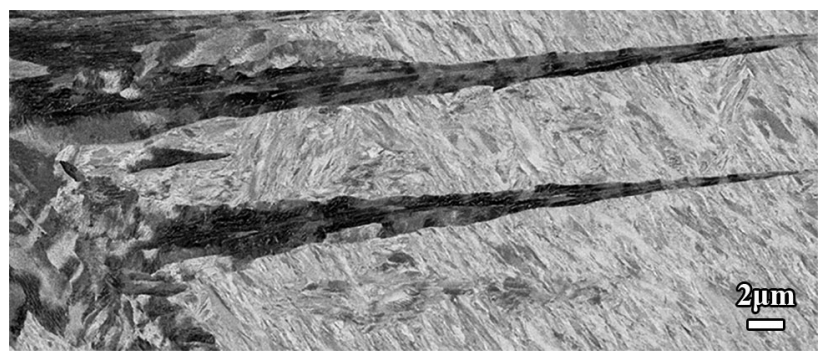

Fig. 17-Two spears of bainite covered by side layers of pearlite. Same specimen as in Fig. 14.

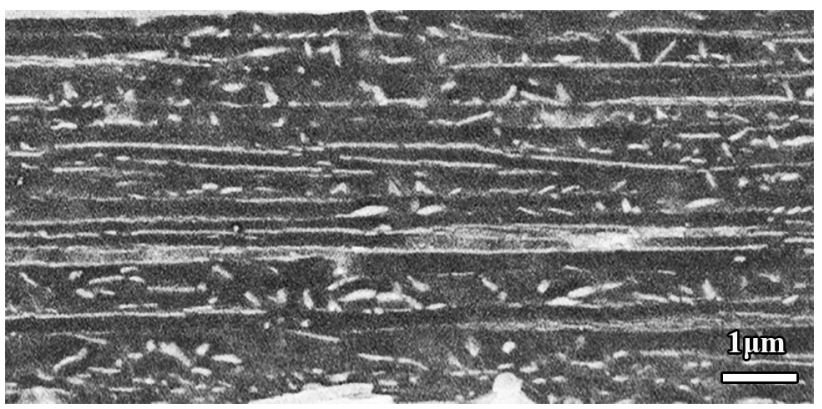

Fig. 18 - Internal morphology of bainite from $773 \mathrm{~K}\left(500{ }^{\circ} \mathrm{C}\right)$, held for $10 \mathrm{~s}$.

the top, in agreement with Figure 21. Figure 22(b) is an EBSD misorientation map, and it demonstrates that the ferritic constituent has the same lattice orientation
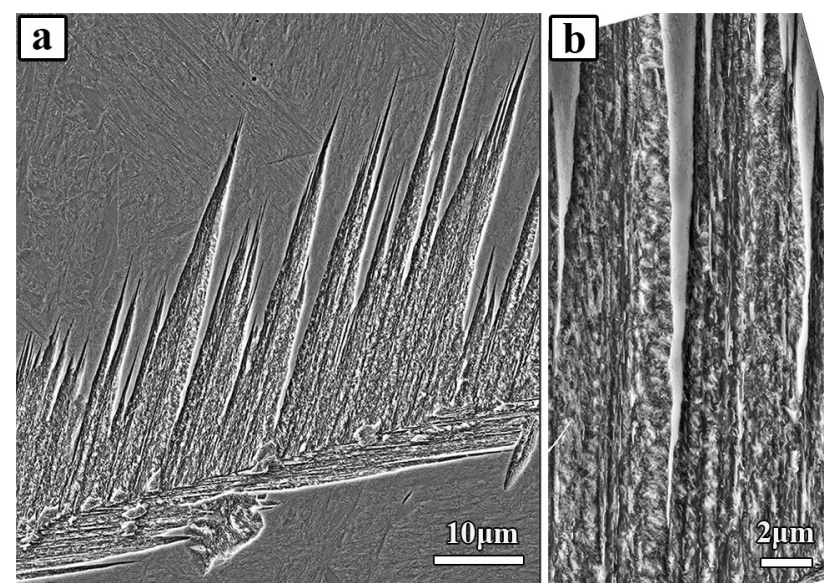

Fig. 19- (a) Part of a feather observed with SEM. Close to the growth front there are wide interspaces remaining between the packets. Side layers are seen on most packets. They are a mixture of ferrite and cementite and the higher magnification in $(b)$ shows sparkle layers which are composed of such mixture. From $723 \mathrm{~K}\left(450{ }^{\circ} \mathrm{C}\right)$ held for $8 \mathrm{~s}$.

within a few degrees, as shown in c, in the whole unit. It may be concluded that the cooperative eutectoid has developed from the primary plate of ferrite.

Part of a feather on both sides of the prior grain boundary is presented in Figure 23 after repolishing and etching of the specimen from Figures 19 through 22. Fine details of the microstructure are now resolved. This feather also shows a mixture of morphologies caused by different thicknesses of the interspaces. As the thickness increases, the long cementite particles are replaced by irregularly shaped particles and then by finer platelets in a regular arrangement, characteristic of a cooperative eutectoid transformation. Close to the upper left corner there is a colony of such microstructure, which is in the process of expanding into the remaining austenite, see the inset in Figure 23.

Small volumes that do not belong to the feather are also seen along the grain boundary in Figure 23. In spite of them, it is evident that all the ferrite plates start from the grain boundary. This indicates that the packets form already in contact to the grain boundary. Figure 24 shows three packets with rather closely spaced plates of 

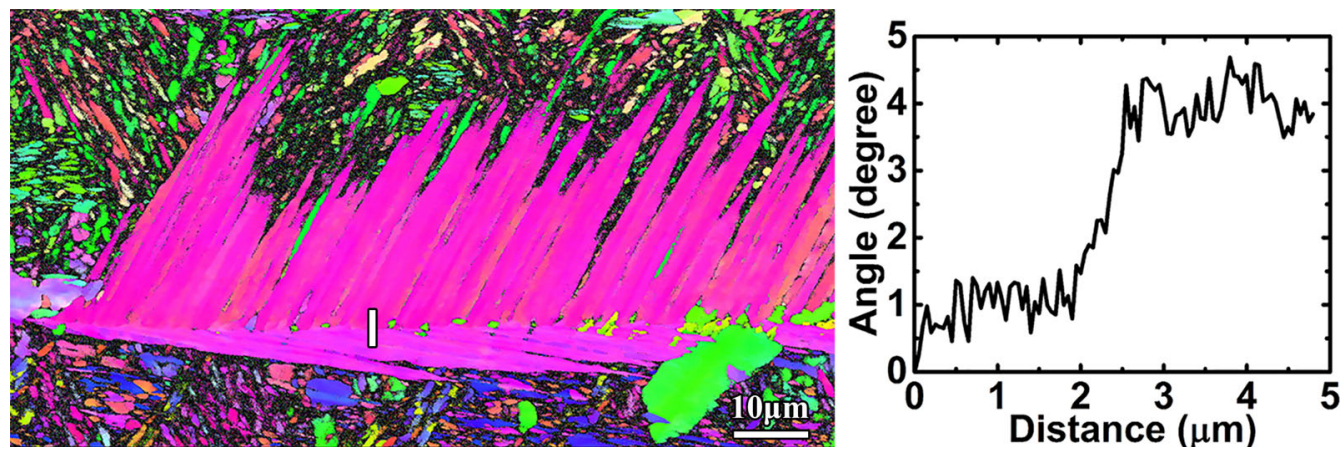

Fig. 20-EBSD IPF map of feather shown in Fig. 19 but in polished state. White line gives the position of misorientation line scan starting from upper part of the feather. From $723 \mathrm{~K}\left(450{ }^{\circ} \mathrm{C}\right)$ held for $8 \mathrm{~s}$.

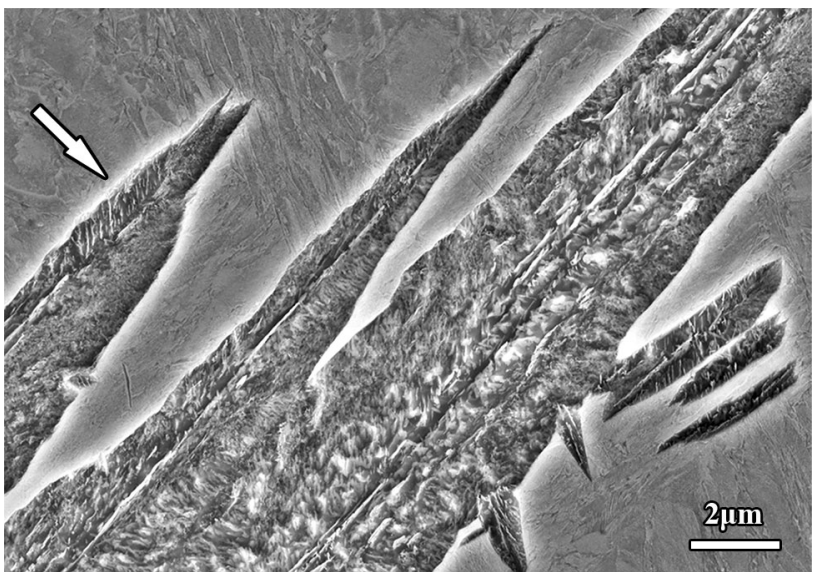

Fig. 21-Another feather from same specimen as in Fig. 19, observed with SEM. The arrow indicates an area where the inner morphology of the side layer is successfully revealed by the etching.
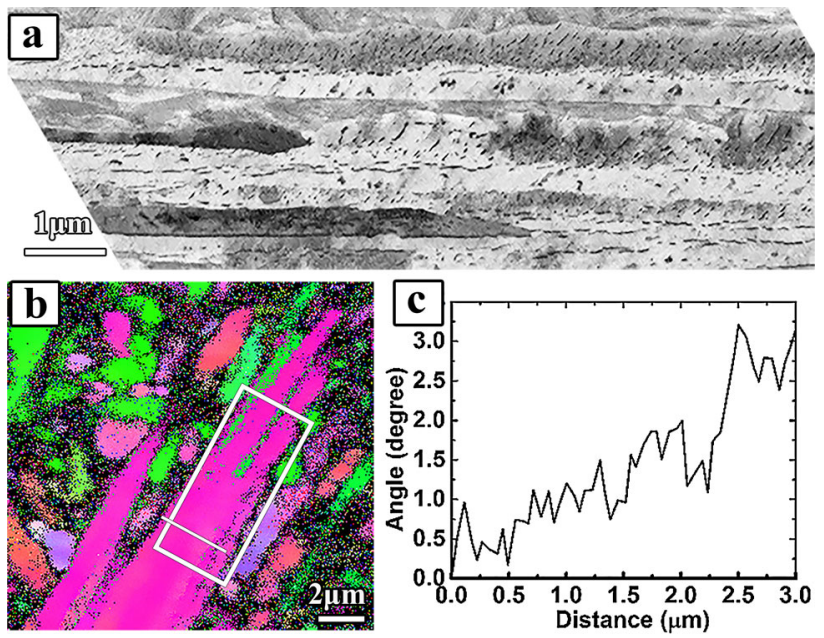

Fig. 22-(a) Region from the feather shown in Fig. 20 and in same polished state but observed with ECCI. Side layer is seen on upper side. (b) EBSD IPF map, the rectangle marks the region shown in (a). (c) Origin-to-point misorientation line scan, indicated by the white line in (b) starting from the left.

ferrite. They are all covered with side-layers. In Figure 24(a), there is a cooperative eutectoid layer on the lower side but the cementite platelets on the upper

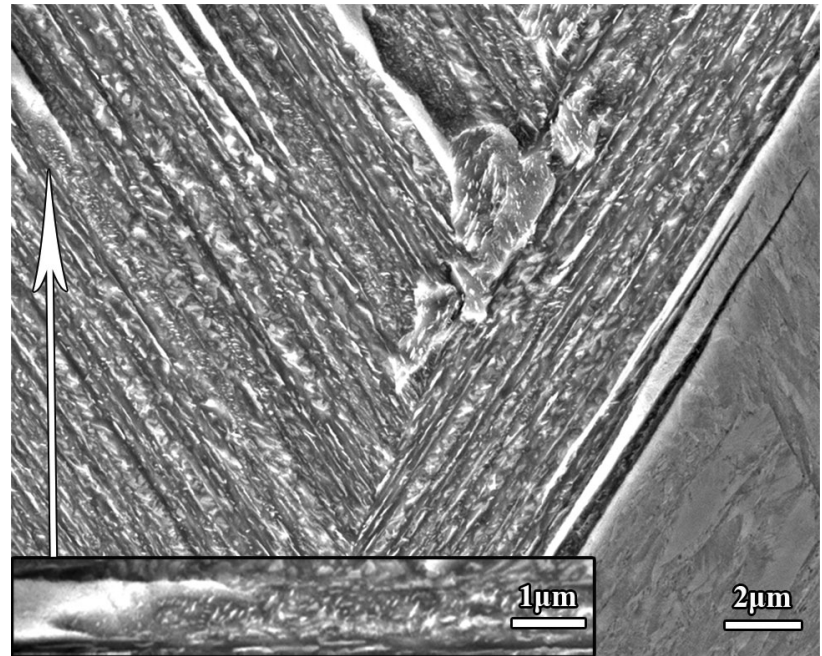

Fig. 23-Both sides of the feather in Fig. 20 after new preparation. Finer details are resolved. Inner structure varies with width of interspaces. In upper left-hand corner, a eutectoid colony is growing into austenite.

side are roughly parallel to the main growth direction. One may consider the possibility that they formed in interspaces in a packet of very thin plates of ferrite but it seems less likely in view of Figure 24(b) where both side-layers on a packet are of that kind and the very irregular interface to austenite on the upper side is far from planar. Figure 24(c) shows a cooperative eutectoid layer on the lower side but not on the upper side. Figure 25 shows a wide packet with a mixture of coarse cementite particles, several colonies of cooperative microstructure inside the wide packet and several areas with cementite platelets that often deviate from the main growth direction. One rather gets the impression that these particles are parts of a two-phase mixture of ferrite and cementite that grows in a direction of free passage. There is also a cooperative side-layer at the upper right corner.

\section{At $673 \mathrm{~K}\left(400^{\circ} \mathrm{C}\right)$}

Similar morphologies as observed at $723 \mathrm{~K}\left(450{ }^{\circ} \mathrm{C}\right)$ were found at $673 \mathrm{~K}\left(400{ }^{\circ} \mathrm{C}\right)$. In the ECCI micrograph in Figure 26(a), there is only degenerate eutectoid 

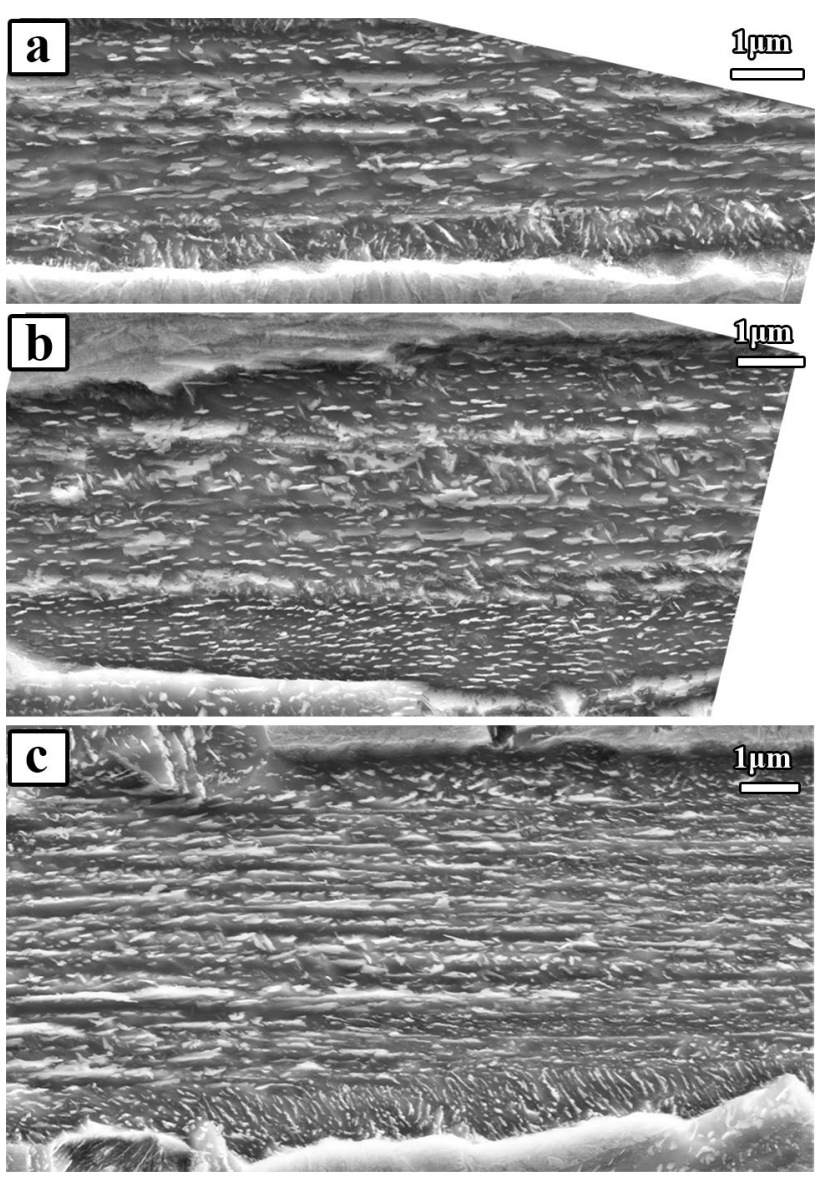

Fig. 24-Three examples of side layers on packets in same specimen as in Figs. 19 through 23 . SEM from $723 \mathrm{~K}\left(450^{\circ} \mathrm{C}\right)$ held for $8 \mathrm{~s}$.

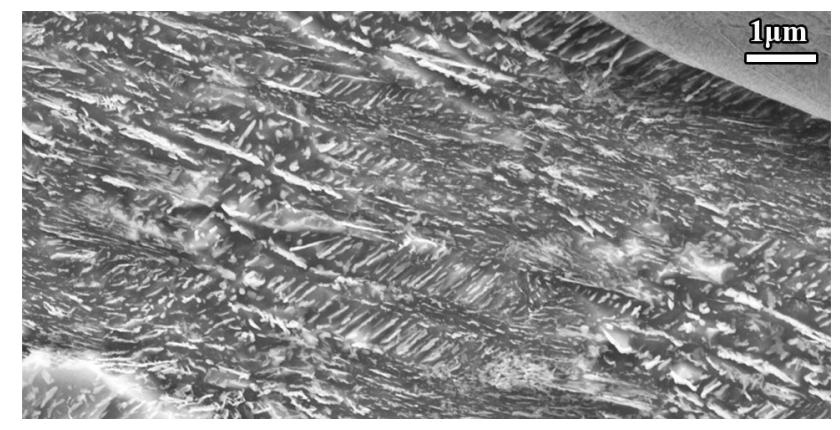

Fig. 25-Thick packet in same specimen as in Figs. 19 through 24, with mixture of eutectoid colonies, elongated cementite particles of various coarseness and thin, untransformed austenite. A eutectoid side layer in the upper right-hand corner. SEM from $723 \mathrm{~K}\left(450{ }^{\circ} \mathrm{C}\right)$ held for $8 \mathrm{~s}$

microstructure with cementite particles elongated in the main growth direction of the ferrite plates. Most of the packets are dark but there is a white one to the right of the middle and also one on the right-hand side. The EBSD micrograph in Figure 26(b) shows that they are of the same variant as the majority. On the other hand, there are some thinner white packets in the left-hand part that belong to another variant and even one that partly looks black in Figure 26(a). It is evident that the
EBSD technique must be employed if it is important to distinguish between variants.

The unit of bainite in Figure 27 has both kinds of eutectoid microstructures. Just above the middle there is a group of very fine ferrite plates outlined by cementite particles elongated in the main growth direction. Further down it is mixed up with the cooperative eutectoid. The lengths of the cementite platelets show that they have formed in thicker interspaces.

There are also several packets in Figure 28(a), and the EBSD micrograph in Figure 28(b) reveals that there are two variants intermixed, Figure 28(c). The thickest one is similar to Figure 27 and contains both types of eutectoid structure which can be seen better in the on-line original.

Both types of eutectoids are found in Figure 29 but there are hardly any elongated cementite particles among the cooperative eutectoid, nor any cooperative eutectoid among the degenerate one. All black and white micrographs from $673 \mathrm{~K}\left(400{ }^{\circ} \mathrm{C}\right)$ were taken with ECCI, and it was difficult to avoid some "clouds" mentioned in Section II.

\section{E. At $623 \mathrm{~K}\left(350{ }^{\circ} \mathrm{C}\right)$}

Figure 30 from $623 \mathrm{~K}\left(350{ }^{\circ} \mathrm{C}\right)$ shows a packet where the primary plates of ferrite can be identified partly by small cementite particles arranged in lines and partly by eutectoid cementite. In Figure 31 there is only cooperative eutectoid but some of the plates of ferrite can be recognized. The inset marks the position of one.

\section{F. At $573 \mathrm{~K}\left(300^{\circ} \mathrm{C}\right)$}

Figure $32(\mathrm{a})$ is a feather from $573 \mathrm{~K}\left(300{ }^{\circ} \mathrm{C}\right)$, and on the right-hand side, there are several thin units that have no contact to the prior grain boundary but are parallel to each other. Nothing similar was observed at higher temperatures. Figure 32(b) is an EBSD micrograph from the same area after a new polish and gives a comparison of the lattice orientation of the long plates of ferrite on the two sides of the prior grain boundary. It was found that it differed by $4 \mathrm{deg}$, which is similar to the result in Figure 20 from $723 \mathrm{~K}\left(450{ }^{\circ} \mathrm{C}\right)$. In addition, this micrograph reveals that the thin units, which are here orange, belong to another variant of ferrite, which occupies a much larger volume than they do according to Figure 32(a). This discrepancy could be due to insufficient etching of this variant and the fact that it is taken after a new polish. It is interesting that the long units are not intersected by the short ones. It seems likely that the short ones have formed after the long ones. It is thus proposed that the long plates came first and have nucleated the new ones, which would not be surprising because intragranular bainite can form at this holding temperature, as illustrated by Figure 33.

Figure 34(a) is from the same feather as Figure 32(a), and Figures 34(b) and (c) are magnifications of the marked area in Figure 34(a). The three longer units in Figure 34(b) were nucleated on the grain boundary and they contain very many cementite particles, somewhat elongated in the main growth direction. They are 
covered with fine cementite particles standing up on the new surface of ferrite after etching. Even ordinary etching procedure gives an effect of deep etching on the fine structures from the lower temperatures. The higher magnification in Figure 34(c) of the top part of the unit to the right in Figure 34(b) shows that those units
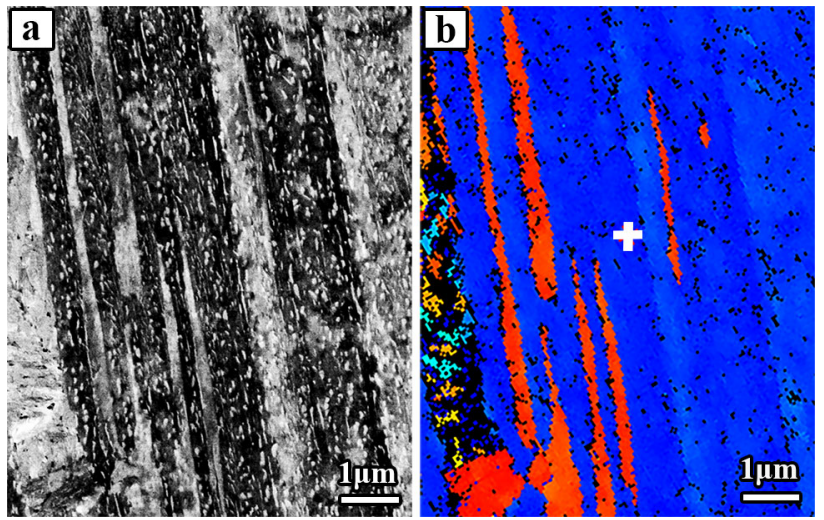

Fig. 26-Degenerate kind of bainite with cementite particles aligned in the main growth direction of ferrite. (a) ECCI and (b) EBSD misorientation map to a reference point, marked with white cross, show that a few units belong a different variant. From $673 \mathrm{~K}$ $\left(400{ }^{\circ} \mathrm{C}\right)$ held for $30 \mathrm{~s}$.

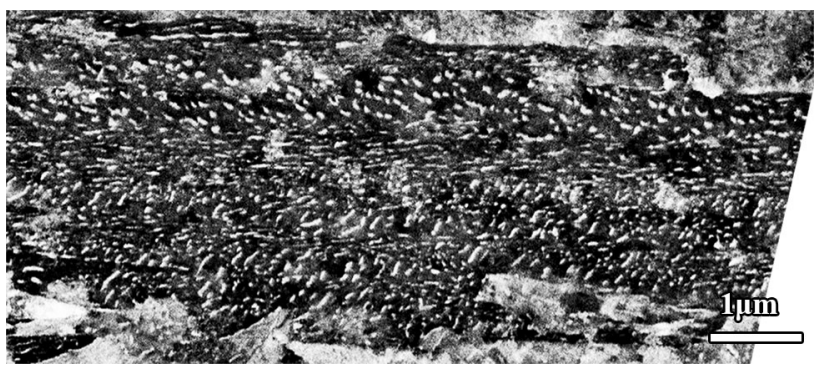

Fig. 27-Bainite unit with a mixture of structures. Just above the middle there is a packet of degenerate kind of bainite with several fine plates of ferrite. The rest is a mixture of the features of both degenerate and cooperative kinds of bainite. ECCI micrograph from $673 \mathrm{~K}\left(400{ }^{\circ} \mathrm{C}\right)$ held for $30 \mathrm{~s}$. contain several fine plates. It is suggested that this unit can be regarded as a packet, and the transformation was completed by the degenerate mode of eutectoid reaction. The three shorter units in Figure 34(b) belong to the orange variant in Figure 32(b) and have the cooperative type of eutectoid microstructure. Figure 35 belongs to the same variant and it demonstrates the cooperative microstructure better and also the lenticular shape, which is not found on the units connected to a grain

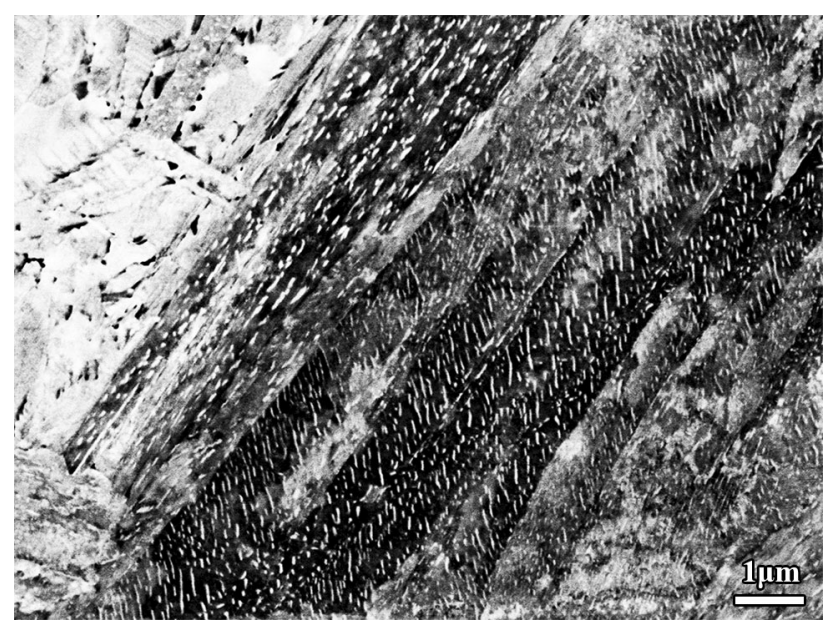

Fig. 29-Two packets of bainite of slightly different directions, one being degenerate, the other being cooperative. ECCI micrograph from $673 \mathrm{~K}\left(400{ }^{\circ} \mathrm{C}\right)$ held for $30 \mathrm{~s}$.

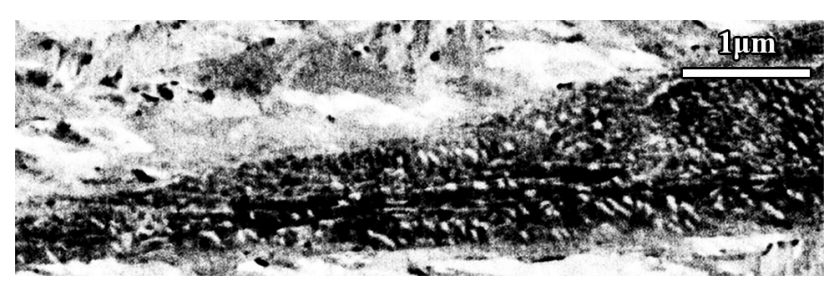

Fig. 30-A packet with similar mixture of morphologies as in Fig. 27. ECCI micrograph from $623 \mathrm{~K}\left(350^{\circ} \mathrm{C}\right)$ held for $50 \mathrm{~s}$.
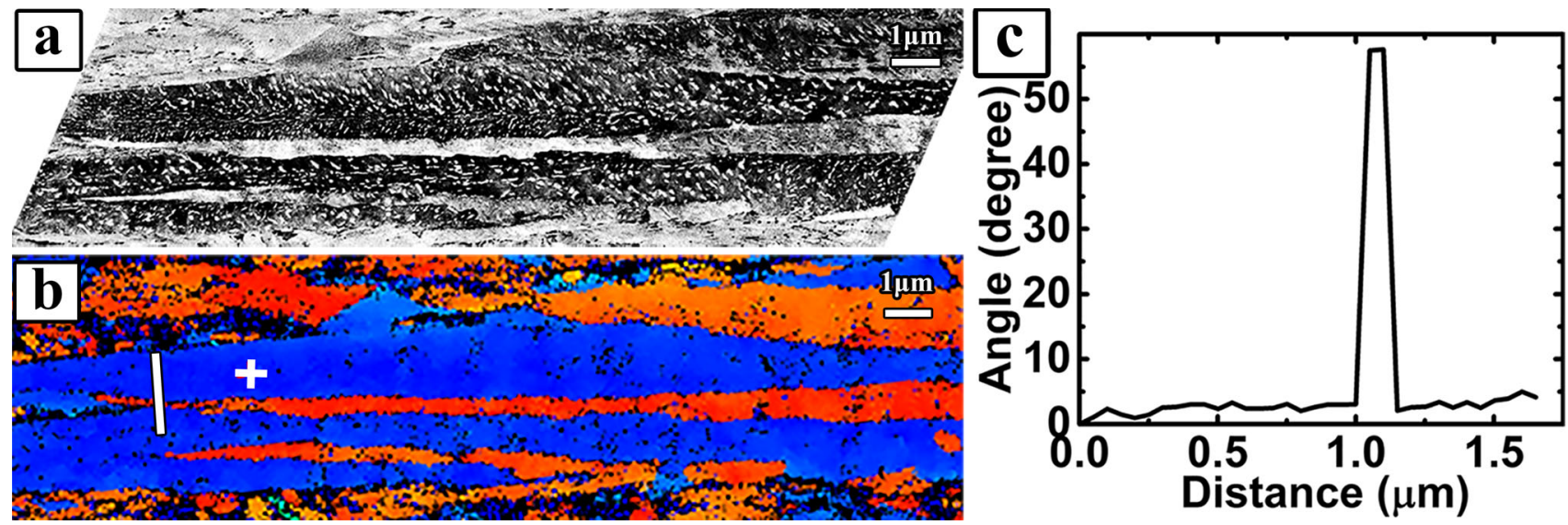

Fig. 28- (a) Similar mixture of morphologies as in Fig. 27. (b) EBSD misorientation map to a reference point, marked with a white cross. (c) The line scan in the position given by the white line shows that the change of ferrite lattice between different morphologies is within 5 degrees. Another variant of ferrite is identified. From $673 \mathrm{~K}\left(400{ }^{\circ} \mathrm{C}\right)$ held for $30 \mathrm{~s}$. 


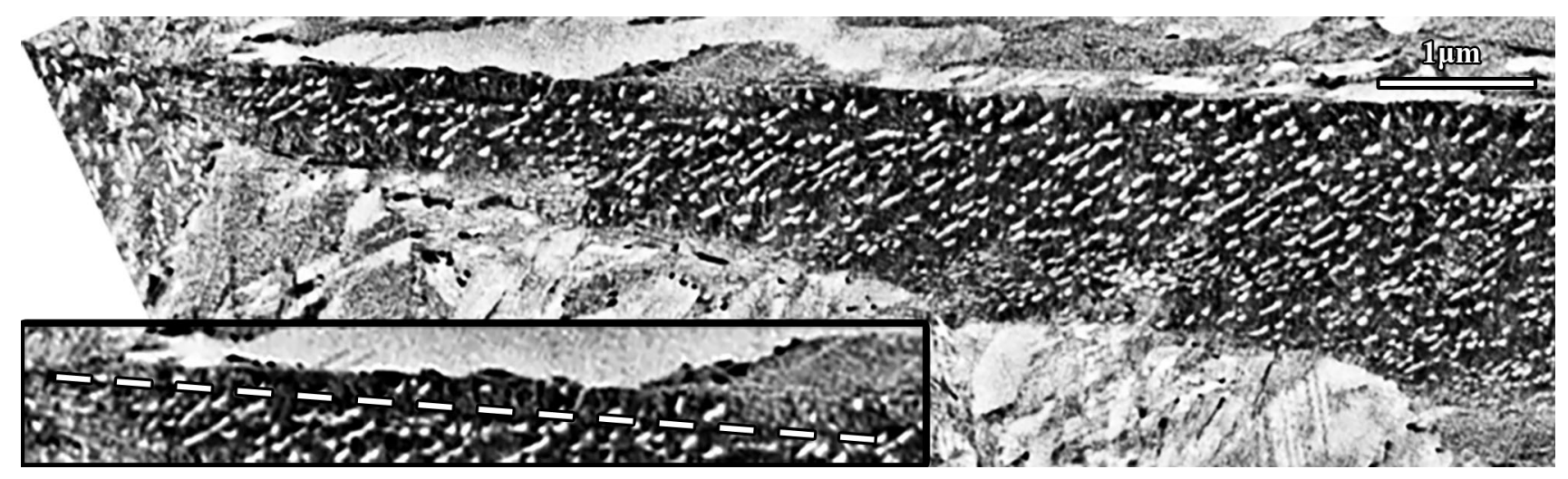

Fig. 31-Packet with predominant cooperative eutectoid feature. The inset illustrates one primary ferrite plate identified close to the very tip. ECCI micrograph from $623 \mathrm{~K}\left(350^{\circ} \mathrm{C}\right)$ held for $50 \mathrm{~s}$.
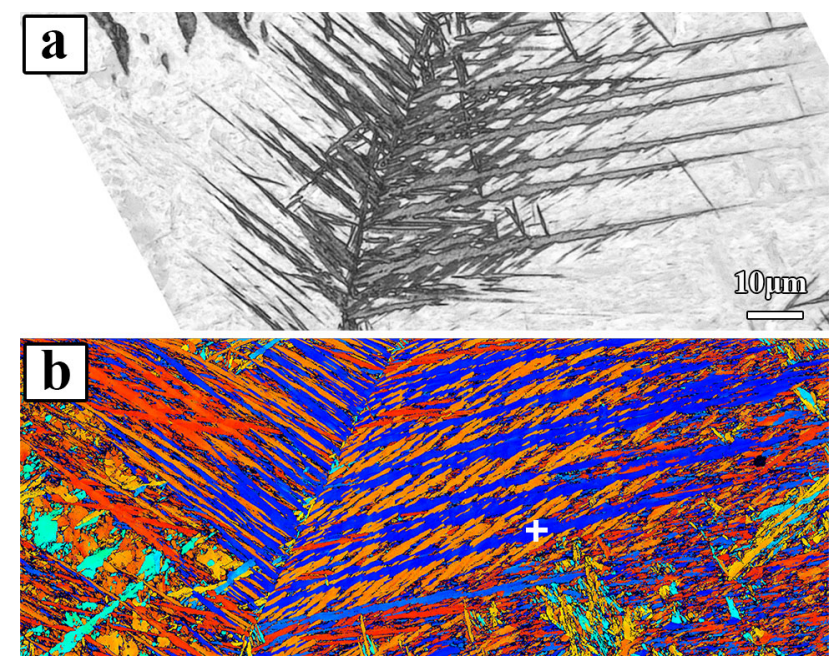

Fig. 32-(a) LOM of feathery bainite with short side plates on the right-hand side. (b) EBSD misorientation map to a reference point, marked with the white cross reveals that all the short side plates have different but uniform orientation. They almost fill the interspaces. Note that (b) is taken after a new polish of (a). From $573 \mathrm{~K}$ $\left(300{ }^{\circ} \mathrm{C}\right)$ held for $60 \mathrm{~s}$.

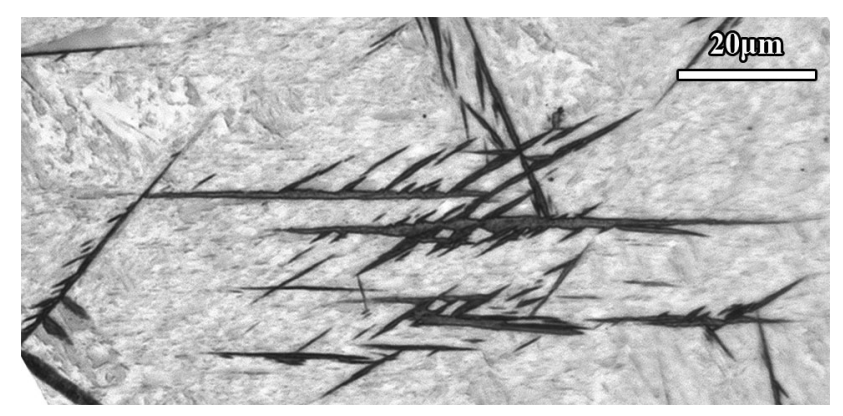

Fig. 33- Short units of bainite nucleated on sides of primary units. LOM from $573 \mathrm{~K}\left(300^{\circ} \mathrm{C}\right)$ held for $60 \mathrm{~s}$.

boundary. It may also be noted that the unit in Figure 35 seems to have close contact with a smooth area on its lower sides and so does the shorter unit above its top. It is proposed that these areas represent single plates of martensite, which have been triggered by the units of bainite on quenching. Figure 36 shows a long unit, which is representative of the other side of the grain boundary where the long units contain very few, maybe only one plate and are covered with side layers of the cooperative type. Figure 37 is a similar example. Oka and Okamoto ${ }^{[27]}$ observed similar units as those in Figures 36 and 37 but simply called the ferrite plates midrib. It should be mentioned that martensite plates, triggered by formation of bainite, are also observed in Figures 36 and 37, all these plates appear smooth and uniform which differs from surroundings.

\section{G. At $548 K\left(275^{\circ} \mathrm{C}\right)$}

Figure 38 shows parallel units of bainite at $548 \mathrm{~K}$ $\left(275^{\circ} \mathrm{C}\right)$, and the magnified inset shows better that there is a single plate of ferrite, surrounded with layers of cooperative eutectoid. There is also a group of four units that may be regarded as a packet. After a longer time, they would probably have merged into one.

\section{DISCUSSION}

\section{A. Origin of Packets and Feathers}

Aaronson and Wells ${ }^{[3]}$ explained that a sheaf of ferrite plates can form by the repeated nucleation of a new ferrite plate in contact with the side of a preexisting plate and by sympathetic nucleation the new plate would obtain the same crystalline orientation. For illustration, they used a micrograph with a few parallel and closely packed plates of ferrite but the plates were displaced lengthwise and the total sheaf was thus longer than each plate. Today, sympathetic nucleation is often used as an explanation of the formation of packets of ferrite plates, which can contain many plates of ferrite. Apparently independent, Goodenow and Hehemann ${ }^{[11]}$ proposed the same kind of process but for the specific purpose of explaining that the lengthening does not occur under diffusion of carbon. Instead, they proposed that the rate of lengthening is controlled by the rate of nucleation of new plates, which grow very quickly by a diffusionless mechanism but only to a limited length. These plates were later regarded as subunits. 

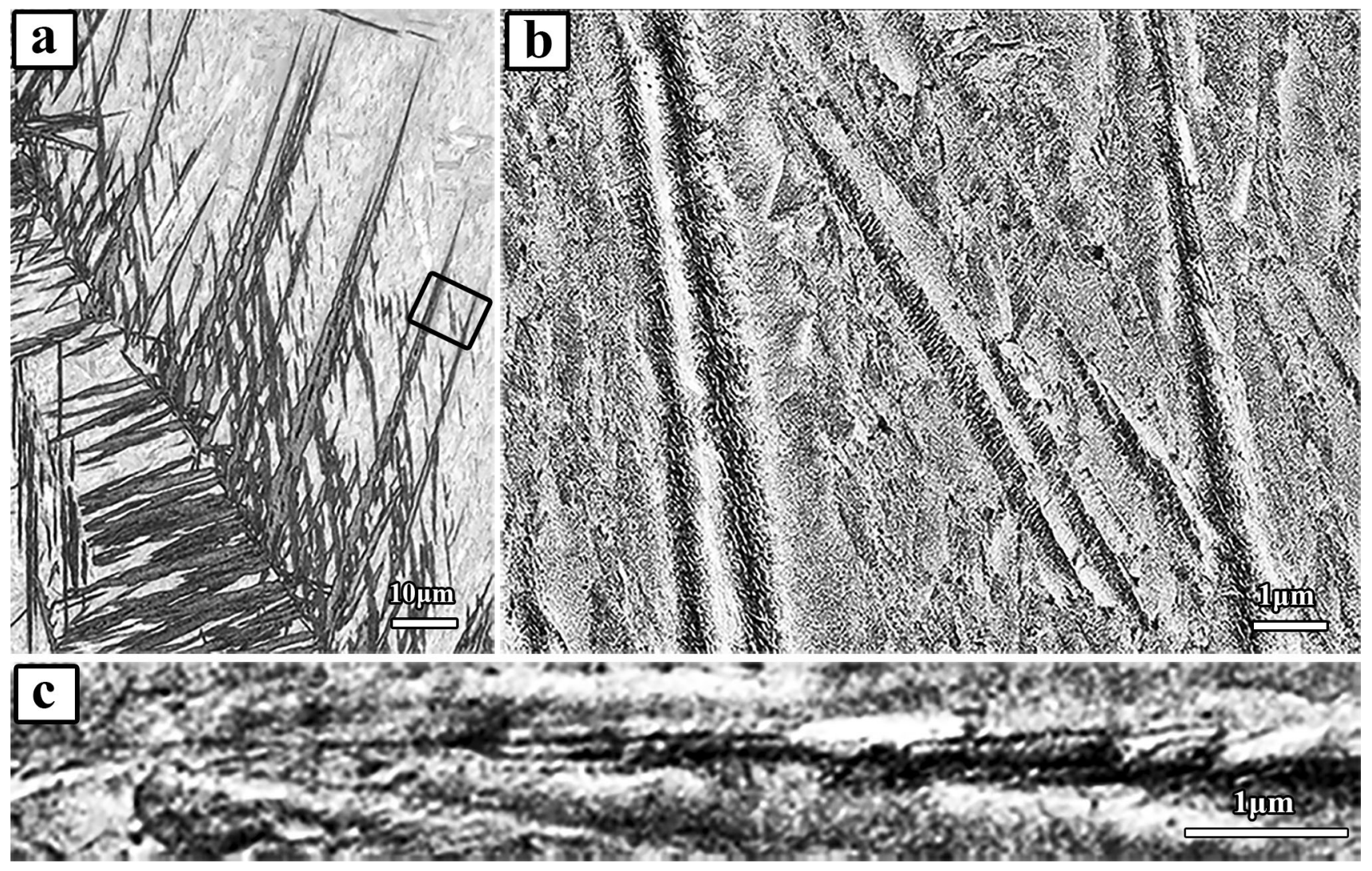

Fig. 34-Same feather as in Fig. 32. (a) LOM and (b) SEM of magnified region marked in (a). The long units, shown to the left, have the degenerate eutectoid feature and seem to be packets composed of several plates of ferrite. The short units in the middle have the cooperative eutectoid feature. (c) The top of the long unit to the right in (b) confirms that the long units contain thin plates of ferrite. From $673 \mathrm{~K}\left(300{ }^{\circ} \mathrm{C}\right.$ ) held for $60 \mathrm{~s}$.

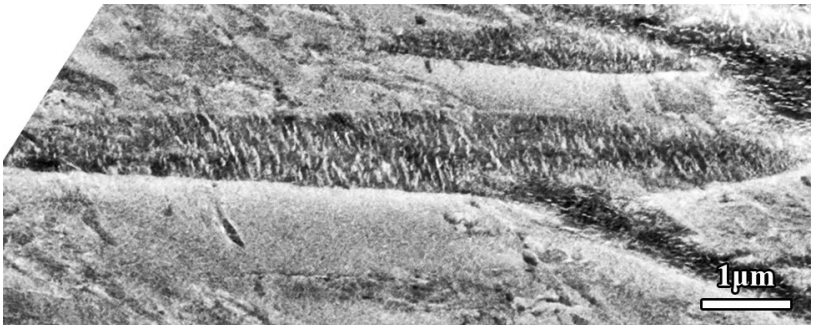

Fig. 35-Higher magnification of the short units shown in Figs. 32 and 34 , confirming the cooperative eutectoid layers. From $673 \mathrm{~K}$ $\left(300{ }^{\circ} \mathrm{C}\right)$ held for $60 \mathrm{~s}$.

Since intragranular nucleation of ferrite could easily be avoided, except for long times and low temperatures, it could often be assumed that all plates of ferrite, examined in the present study above $623 \mathrm{~K}\left(350^{\circ} \mathrm{C}\right)$, were nucleated on grain boundaries. Figure 39 shows two grains, meeting at a grain boundary, and plates that have started from the grain boundary. However, on the upper side of the grain boundary, there are many cross sections of plates without contact to this grain boundary. It may be concluded that they were nucleated on another grain boundary, situated above or below but roughly parallel to the plane of polish. The short length of these plates indicates that they are lath-like and that length in the polished section may be close to the actual

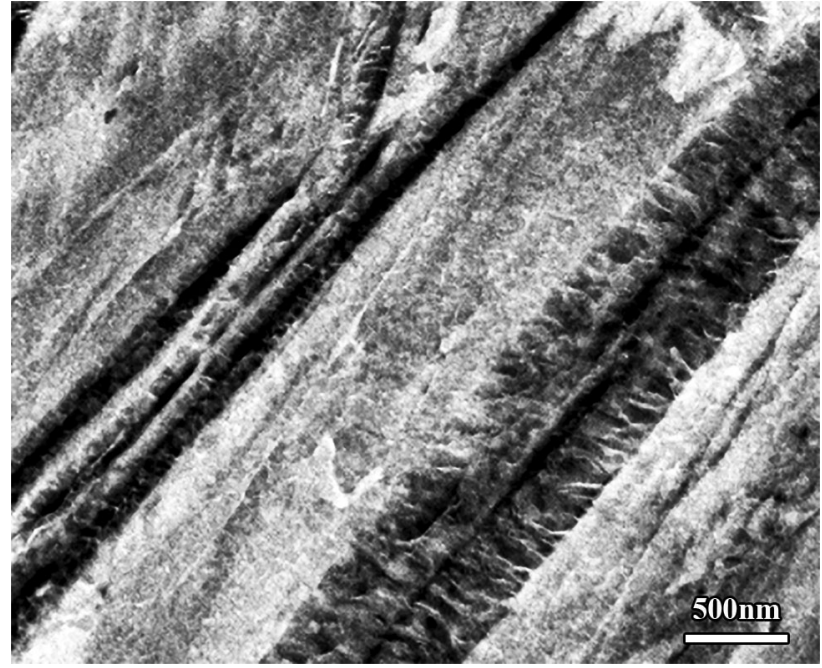

Fig. 36 - Long units of bainite starting from a grain boundary. The thick unit has typical side layers of cooperative eutectoid. Layers have just started to develop on the sides of three thin plates to the left. SEM from $673 \mathrm{~K}\left(300^{\circ} \mathrm{C}\right)$ held for $60 \mathrm{~s}$.

width of lath-like plates. A great majority of the cross sections are parallel, which is certainly related to the observation that most ferrite particles, nucleated on the same grain boundary, often have the same kind of 


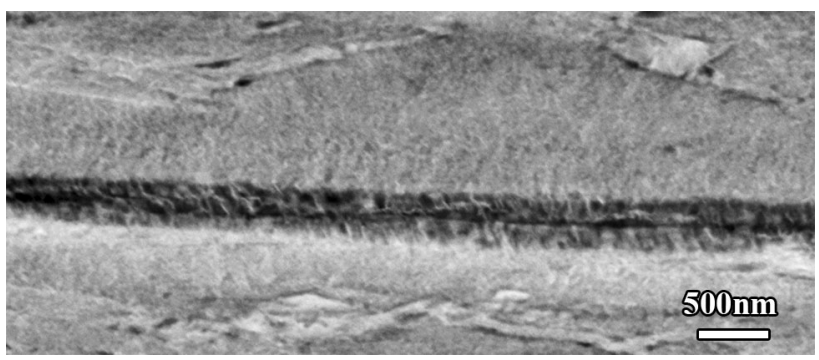

Fig. 37-Long unit of bainite showing typical side layers, surrounded by thick layers that are fairly homogeneous, probably untempered martensite. SEM from $673 \mathrm{~K}\left(300{ }^{\circ} \mathrm{C}\right)$ held for $60 \mathrm{~s}$.

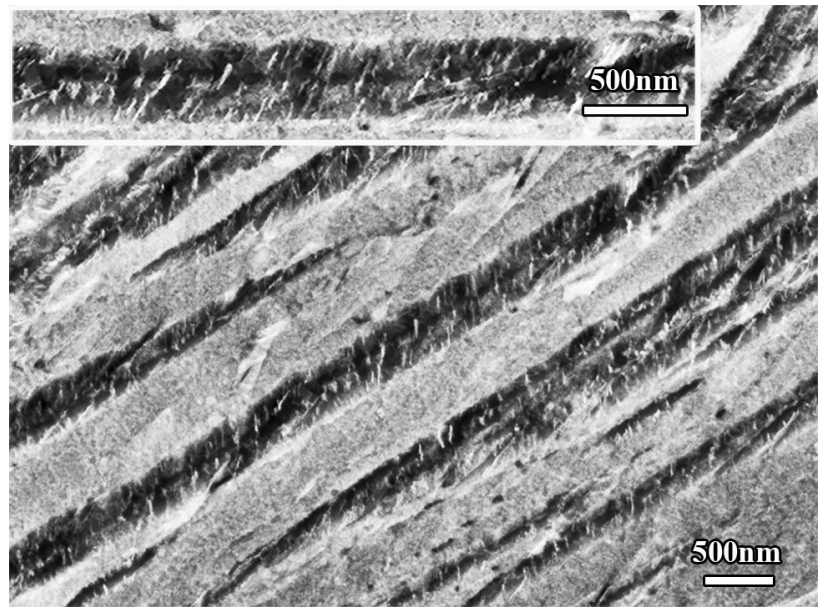

Fig. 38-Units of bainite usually containing only one plate of ferrite with side layers. SEM from $548 \mathrm{~K}\left(275^{\circ} \mathrm{C}\right)$ held for $45 \mathrm{~s}$.

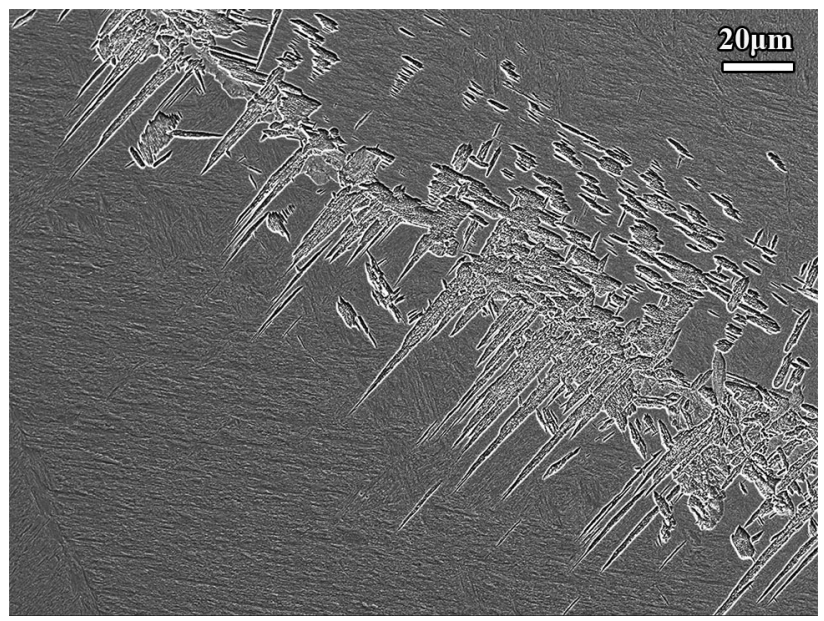

Fig. 39-Packets on two sides of a grain boundary. The long ones are shown from their nucleation site on the grain boundary and to the growing top. The short ones are shown in cross sections and nucleated on another grain boundary above or below the plane of polish. SEM from $723 \mathrm{~K}\left(450{ }^{\circ} \mathrm{C}\right)$ held for $8 \mathrm{~s}$.

shape ${ }^{[15]}$ and may thus have the same crystalline orientation. An interesting feature of the upper grain in Figure 39 is that most of the plates are collected in groups, which are certainly cross sections of packets often observed in sections closer to the main growth direction of the plates. The plates in a packet are placed side-by-side in most of these cross sections and all of them may have nucleated in contact with the grain boundary because it was observed, e.g., in Figure 23 from $723 \mathrm{~K}\left(450^{\circ} \mathrm{C}\right)$, that all plates of a packet existed already close to the grain boundary. That they developed at an early stage at this temperature was demonstrated also by the chevron in Figure 3(a) which can be seen to consist of several units. One may only speculate whether one plate stimulated the nucleation of the next one on the grain boundary or the grain boundary had some special properties along a certain line.

If the specimen in Figure 39 had been sectioned perpendicular to the present plane of polish and also perpendicular to the cross sectioned plates, the new section could have displayed packets closer to their length direction and also another grain boundary where they nucleated. The section would also have shown similar packets on the other side of that grain boundary if the plates had started from chevron particles. It may be concluded that all the plates in a feather have not formed one after the other along the whole grain boundary, nor by random nucleation.

Figure 39 also supports indirectly that the plates of a packet have not been nucleated away from the grain boundary, as previously suggested. The hypothesis that plates of bainitic ferrite lengthen by the repeated nucleation of subunits that grow rapidly to a limited length of about $10 \mu \mathrm{m}^{[11,12]}$ was conclusively disproved already by the in-situ observation in a high-voltage electron microscope by Nemoto ${ }^{[28]}$ that the growth is continuous even down to a resolution of $0.1 \mu \mathrm{m}$. Obviously, his result was not noticed when the hypothesis of discontinuous growth by Goodenow and Hehemann ${ }^{[11]}$ was gaining new support by the discovery that the $\mathrm{B}_{\mathrm{S}}$ temperature of steels could be predicted reasonably well for $\mathrm{Mn}$ and $\mathrm{Ni}$ steels on thermodynamic grounds. $^{[29,30]}$

Continuous lengthening has recently been confirmed several times with the use of confocal microscopes. ${ }^{[31-34]}$ New conclusive evidence was obtained in the preceding paper on the morphology of proeutectoid ferrite by the observation of plates formed under continuous growth during decreasing temperature, Figures 36 and 37 in Reference 15. On the other hand, it does not seem possible to deny the atom probe tomography (ATP) work showing that bainitic ferrite can have much higher carbon contents than predicted by available thermodynamic information. ${ }^{[35-37]}$ From this point of view, it may still seem feasible that the fine cementite particles in lower bainite form by precipitation from supersaturated ferrite. The opposite alternative is that these particles are constituents of eutectoid colonies as suggested by Hillert $^{[4]}$ as an explanation of the occasional presence of two-phase colonies in upper bainite. More recently, that was supported by a review of similar metallographic observations. ${ }^{[38]}$ In the preceding study, ${ }^{[17]}$ there were further observations of a two-phase colony in contact with cementite-free ferrite and carbon-enriched interspace. The shapes of those colonies relative to the surroundings were such that they could only be explained as the result of a eutectoid transformation. 
That conclusion has now been further supported by the observation that the eutectoid ferrite is part of the same crystal as the carbon-free ferrite.

\section{B. The Two Modes of the Second Stage}

It was the main purpose of the present work to examine whether there is a continuous change from the occasional eutectoid colonies at higher temperatures to their predominance at lower temperatures. Such a result would be a strong indication that not even the fine cementite particles in lower bainite have formed by precipitation from supersaturated ferrite. In fact, this goal was also behind the preceding study of the second stage of bainite formation but could not be attained due to the high $\mathrm{M}_{\mathrm{S}}$ temperature, probably close to $673 \mathrm{~K}$ $\left(400{ }^{\circ} \mathrm{C}\right.$ ), of the alloy with 0.3 mass pct carbon. The critical temperature of lower bainite is generally given as about $623 \mathrm{~K}\left(350{ }^{\circ} \mathrm{C}\right) .{ }^{[39,40]}$ The present alloy has 0.7 mass pct carbon and an estimated $\mathrm{M}_{\mathrm{S}}$ temperature of $539 \mathrm{~K}\left(266^{\circ} \mathrm{C}\right)$. There was thus a temperature range open for the present study of lower bainite in this alloy.

In the preceding study of the second stage of formation of upper bainite, ${ }^{[17]}$ the focus was on the transformation of austenite in the interspaces between ferrite plates. In typical upper bainite, elongated cementite particles will precipitate in interspaces but it was emphasized that there must be a simultaneous formation of ferrite and one should thus consider the formation of cementite as part of a eutectoid transformation and not as a precipitation reaction, which is the generally accepted hypothesis. Following an old suggestion, ${ }^{[4]}$ two modes of the eutectoid transformation were considered, the degenerate and cooperative ones. The coarse cementite particles, typical of upper bainite and elongated in the main growth direction, were considered as the result of a degenerate eutectoid transformation and the cementite platelets of a different orientation were considered as constituents of two-phase colonies, formed by cooperative growth. From this understanding, one might expect also to be able to distinguish the primary plates of ferrite, free of cementite, but that was not always the case. One reason could be that SEM was used as a convenient method to achieve higher magnification.

Figure 18 is an ECCI micrograph of a packet of bainite from $773 \mathrm{~K}\left(500{ }^{\circ} \mathrm{C}\right)$, and it is evident that even with ECCI it can sometimes be difficult to identify some cementite-free plates. However, it should be realized that most of the plates that can be identified are now surrounded by thin white lines that represent interspaces in their final state of thin austenite with high carbon content. The transformed interspaces may have started to transform at an earlier state when the ferrite plates were still much thinner. It would be difficult to identify such plates when surrounded by a mixture of ferrite and irregular cementite particles. Figure 26 is an ECCI micrograph from $673 \mathrm{~K}\left(400{ }^{\circ} \mathrm{C}\right)$ and all the interspaces have been transformed. Many of the cementite particles are elongated in the main growth direction as a memory of the directions of the interspaces but it is still difficult to recognize individual cementite-free plates of ferrite.
In the lower half of Figure 27, there are many cementite platelets of the cooperative type. Comparison of their lengths with the thicknesses of ferrite plates, indicated by elongated platelets of cementite in the band just above the middle of the micrograph, shows that the cooperative type of cementite has formed in interspaces much wider than the prior interspaces in that band. Figure 28(a) is another ECCI micrograph from $673 \mathrm{~K}$ $\left(400{ }^{\circ} \mathrm{C}\right)$ and the thick unit has the same mixture of cooperative and degenerate eutectoid microstructures as shown in Figure 27. Figure 28(b) is an EBSD micrograph of the same area and it demonstrates that the ferritic constituent in the whole unit has the same lattice orientation. There are also other units of a different variant and the two are intermixed. The ECCI micrograph in Figure 29 also shows both kinds of microstructures but in two different units of bainite.

In the ECCI micrograph from $623 \mathrm{~K}\left(350{ }^{\circ} \mathrm{C}\right)$ as shown in Figure 30, one can see series of small cementite particles outlining prior interspaces although there are also platelets reminding of the cooperative type. Figure 31 shows only the cooperative type. In the SEM micrograph as shown in Figure 34(b) of an etched specimen from $573 \mathrm{~K}\left(300{ }^{\circ} \mathrm{C}\right)$, the two units of bainite on the left-hand side and the one on the right-hand side have very many small cementite particles in the main growth direction. That morphology is recognized from the side layers in Figure 24(b) at $723 \mathrm{~K}\left(450^{\circ} \mathrm{C}\right)$ and from the unit to the left in Figure 26(a) at $673 \mathrm{~K}$ $\left(400{ }^{\circ} \mathrm{C}\right)$. It should thus have formed by the degenerate mode of eutectoid transformation and these units of bainite should thus be packets of several plates of ferrite. That is supported by Figure 34(c) showing thin plates of ferrite at the very top of the single long unit where the eutectoid transformation has not yet occurred. The three smaller units in Figure 34(b) show the cooperative type. This is better illustrated in Figure 35, which shows another unit of the same family of parallel units of bainite.

In the preceding study of proeutectoid ferrite, ${ }^{[15]}$ it was concluded that feathery bainite can develop from grain boundaries with a series of ferrite particles shaped as chevrons. It is thus interesting that both features, feathers and chevrons, were now observed in the whole range of temperature, in particular a series of chevrons as well as feathers at $573 \mathrm{~K}\left(300^{\circ} \mathrm{C}\right)$, Figures 7 and 8 . In the whole range, there was a variety of feathery structures from more or less complete feathers or semi-feathers to incomplete feathers and more dispersed parallel packets.

The SEM micrographs in Figures 36 and 37, also from $573 \mathrm{~K}\left(300^{\circ} \mathrm{C}\right)$, show only one or two plates of ferrite and the second stage of bainite formation has only resulted in side layers formed by the cooperative mode. The SEM micrograph from $548 \mathrm{~K}\left(275^{\circ} \mathrm{C}\right)$ in Figure 38 also shows long bainite units from a feather. They also have side layers of the cooperative mode and seem to have only one plate of ferrite. In that case, there has not been any interspace.

In summary, for the degenerate mode of transformation, it is sometimes difficult to recognize the plates of ferrite. The cementite constituent of the degenerate 
eutectoid is elongated or more or less irregular at the higher temperatures but consists of small or slightly elongated particles at the lower temperatures. It is difficult to recognize the plates of ferrite if the cooperative eutectoid predominates. Ferrite in the cooperative eutectoid has the same lattice orientation as in the adjoining plates of ferrite. It may be concluded that the internal structure of bainitic units nucleated at grain boundaries is not much affected by the temperature of formation from $773 \mathrm{~K}$ to $548 \mathrm{~K}\left(500{ }^{\circ} \mathrm{C}\right.$ to $\left.275^{\circ} \mathrm{C}\right)$.

\section{Definition of Upper and Lower Bainite}

There has been an on-going discussion how the difference between upper and lower bainite should be defined but it has been complicated due to a simultaneous discussion on mechanisms. When Mehl ${ }^{[1]}$ introduced the terms upper and lower bainite, he simply exemplified upper bainite with feathery bainite on grain boundaries and lower bainite with intragranular units. Most certainly, Mehl and many others had noticed morphological difference also with regard to the distribution of cementite within various types of bainite. Hillert ${ }^{[4]}$ noted that the elongated particles of cementite in upper bainite were sometimes replaced by a more intimate mixture of ferrite and cementite. He also noticed that the same two-phase mixture could appear on the side of a feather. From his background in diffusional transformations, he concluded that the normal morphology of upper bainite was due to a degenerate eutectoid transformation and the other morphology was due to a cooperative eutectoid transformation. He suggested the possibility that the second mode would grow more important at lower temperatures. Matas and Hehemann ${ }^{[6]}$ must have noticed the same difference in morphology but, from the idea that primary ferrite forms without diffusion of carbon, they proposed that carbon was ejected from the supersaturated ferrite and precipitated as elongated cementite particles in the austenitic interspaces in upper bainite, whereas carbon precipitated directly in the supersaturated ferrite and formed small platelets in a different direction in lower bainite. From a morphological point of view, there was no difference between the two approaches. These morphologies have been widely accepted as the difference between upper and lower bainite although it is mostly connected with the idea of diffusionless growth of the plates of ferrite. Of course, this definition concerns the internal morphology and, in practice, only the cementite particles. On the other hand, Vilella ${ }^{[41]}$ already long ago claimed that there is no sharp transition between the two but a gradual change of the volume fractions from $723 \mathrm{~K}$ to $573 \mathrm{~K}\left(450{ }^{\circ} \mathrm{C}\right.$ to $\left.300{ }^{\circ} \mathrm{C}\right)$ which should cover the transition temperature from upper to lower bainite if it exists. Pickering ${ }^{[39]}$ made a similar statement. No major transition of the internal morphology was found in the present work or in the two preceding studies. ${ }^{[15,17]}$

Of course, it could make sense to define the limiting cases as long as it is realized that there is no sharp dividing line. The only way to define a sharp dividing line may be to accept Mehl's approach and to divide between grain boundary and intragranularly nucleated bainite. Another alternative, which has been discussed by Ohmori et al. ${ }^{[13]}$ is based on the effect of the primary plates of ferrite on the characteristics of a unit of bainite. However, this is also a feature that changes gradually. It could finally be emphasized that the hypothesis of cementite precipitating from supersaturated ferrite in lower bainite implies a sharp transition between two mechanisms but that would not imply a sharp transition between them with temperature. From these results, it does not seem wise to define a transition between upper and lower bainite based on the inner morphology of the bainite units. Mehl's definition based on the nucleation site seems much preferable.

\section{Side Layers}

At the lower right-hand corner of Figure 12 from $823 \mathrm{~K}$ $\left(550^{\circ} \mathrm{C}\right)$, there are two long cementite particles between plates of ferrite at the side of a packet. They suddenly change growth direction and seem to start collaborating with ferrite in forming a layer of cooperative eutectoid. This change could hardly happen unless the cementite particles had reached contact with the parent austenite while growing in the main growth direction. One may guess that the cementite particles were close behind the growth front already before the change. In fact, that was already noticed when this feathery microstructure was not accepted as bainite in Section IV-A. In this respect, and with the ability to form a eutectoid side layer, this case resembles what was called columnar bainite in a steel with 0.82 mass pet carbon at $30 \mathrm{kbar}$ and $563 \mathrm{~K}\left(290{ }^{\circ} \mathrm{C}\right) .{ }^{[42]}$

As shown in Figures 14, 15, and 16 from $773 \mathrm{~K}$ $\left(500{ }^{\circ} \mathrm{C}\right)$, pearlite has a tendency to cover the sides of packets of ferrite plates. Figure 17 demonstrates that the pearlitic side layer can reach close to the advancing tip of ferrite (more clearly seen in the on-line version). It thus illustrates that pearlite at $773 \mathrm{~K}\left(500{ }^{\circ} \mathrm{C}\right)$ can cover the broad faces of ferrite plates with a layer that grows along the broad faces much faster than into the free volumes of austenite.

Figure 19(a) demonstrates that similar side layers also form at $723 \mathrm{~K}\left(450{ }^{\circ} \mathrm{C}\right)$ on the sides of ferrite plates in feathery bainite. However, the EBSD map in Figure 20 shows that the ferritic constituent of these layers has almost the same lattice orientation because there is no obvious difference in color. The misorientation line scan, covering parts of both sides of the feather, illustrates that already an orientation difference of about $3 \mathrm{deg}$ gives a noticeable difference in color. Figure 21 is from another feather in the same specimen, where the etchant has attacked part of the side layer in a different way. It is thus revealed that this layer consists of the cooperative eutectoid. Figure 22(a) confirms the result from Figures 21 and 22(b), which demonstrates that there are only small variations in orientation. It is thus confirmed that the ferrite in the cooperative eutectoid and ferrite in the adjoining plate have practically the same orientation.

The three SEM micrographs in Figure 24 show rather thick packets of ferrite plates, also from $723 \mathrm{~K}\left(450^{\circ} \mathrm{C}\right)$. In Figures 24(a) and (c), there is a layer of cooperative eutectoid on the lower side of the packets. On their upper sides and on both sides in Figure 24(b), there is a different kind of layer with many small cementite platelets in the 
main growth direction. It is proposed that they have formed by the degenerate eutectoid transformation of interspaces that were thinner than inside the packets. Similar small cementite platelets can occasionally be seen also inside the coarse packets. It may seem that there was first a more widely spaced group of ferrite plates and more finely spaced plates formed later in some of the wider interspaces and on the sides of the group.

In Figure 21, there are two wide interspaces between plates or packets and they are being filled by side layers. For the interspace closest to the center of the micrograph, it is interesting that at this magnification there is no indication of the prior interspace after it has been closed. This case resembles case (d) in Figures 24 and 25 of Reference 17.

Close to the upper left-hand corner of Figure 23, there is an example of a cooperative eutectoid colony spreading along the side of one of the two ferrite plates defining an interspace. Further back it has been able to transform the whole width of the interspace. It is evident that there is no difference between the cooperative eutectoid found somewhere inside a packet or on its side. It is suggested that in a thinner interspace the colony would touch both plates, which could disturb the cooperation and degenerate the eutectoid reaction.

Figure 36 demonstrates that the cooperative layer has started to form even in the three thin units, giving the impression that it is difficult to avoid side layers on ferrite plates at this temperature, which was $573 \mathrm{~K}\left(300{ }^{\circ} \mathrm{C}\right)$. However, the three long units in Figure 34(b) have no side layers. On the other hand, Figure 34(c) illustrates the ferrite plates at the tip and it is evident that the microstructure will soon be modified by the occurrence of cementite. One may speculated that the broad faces of these plates are very coherent and not able to modify the structure enough to cooperate with cementite in a eutectoid reaction. Such a modification may be necessary for cooperative growth, as proposed already in the preceding study ${ }^{[17]}$ of the second stage of bainite formation in steels with 0.3 mass pct carbon. It may be significant that the present two different cases were observed on long units of the same feather but on different sides. Furthermore, the similarity in color between long units on the two sides of the grain boundary in Figure 32(b) indicates that they could originate from common chevrons. An examination with EBSD showed that the orientation difference between the long units on the two sides, blue in Figure 32(b), was only 5 degrees, indicating that they have actually formed from chevrons. In the study of proeutectoid ferrite, ${ }^{[15]}$ it was realized that the grain boundary particles could hardly have a strict orientation relationship to both austenite grains even when they have facets to both grains as chevrons do. It is thus suggested that only the long plates on one side of the grain boundary had sufficiently good orientation matching to avoid cooperative growth.

\section{SUMMARY AND CONCLUSIONS}

The results of the present study are in general agreement with the classical study of a eutectoid steel by Modin and Modin, ${ }^{[43]}$ which was carried out with electron microscopy on plastic replica. However, the higher resolution obtained with modern techniques has increased the possibility to study finer details.

By avoiding low temperatures and long holding times, it is possible to prevent intragranular nucleation of ferrite in the Fe-C alloy with 0.7 mass pct carbon. All nucleation of ferrite particles would then occur on grain boundaries and, depending on the crystallography of the grain boundary, the particles will develop into plates of a certain direction. They form in groups of parallel plates and will thus develop as packets of ferrite plates. The first plate will in some way stimulate the formation of another particle in the neighborhood on the grain boundary etc. However, it is not evident by what mechanism this repeated nucleation could happen. It has been suggested that packets form by this process of stimulated nucleation but in direct contact to a previous plate and without contact to a grain boundary. That was not observed in the present work.

Similar groups form on random sites on the grain boundary and in a simple case all plates from a grain boundary are parallel but sometimes more than one family can form. On several grain boundaries, the ferrite particles can develop plates into both austenite grains and with a chevron pattern in a plane of polish. If nothing else nucleates on the grain boundary, it will finally be filled with groups of plates or chevrons. In a plane of polish, the chevrons will look as a feather. The simple plates will only grow into one grain and together look as half a feather, a semifeather. If a grain boundary has not been filled with groups, there will be a more incomplete feather or semifeather composed of separated packets of ferrite plates. That will also happen if there is competition from another family of ferrite particles on the grain boundary.

Packets of plates were found in the whole temperature range from $773 \mathrm{~K}$ to $548 \mathrm{~K}\left(500{ }^{\circ} \mathrm{C}\right.$ to $\left.275^{\circ} \mathrm{C}\right)$ but the individual plates are sometimes difficult to see depending on the morphology of the cementite particles formed in the second stage of bainite formation. The cooperative mode of eutectoid transformation gives less direct indications of primary ferrite plates but the length of cementite platelets in eutectoid colonies gives indirect information on the distance between ferrite plates. The free tops of plates at the growth front clearly show that the first stage of bainite formation is the primary precipitation of ferrite plates.

At $623 \mathrm{~K}\left(350{ }^{\circ} \mathrm{C}\right)$, there can still be many plates in most packets, and for $573 \mathrm{~K}\left(300{ }^{\circ} \mathrm{C}\right)$ there were some packets with several plates and some with very few primary plates. At $548 \mathrm{~K}\left(275^{\circ} \mathrm{C}\right)$, all units seemed to have only one plate. Intragranular ferrite was difficult to avoid at $573 \mathrm{~K}\left(300{ }^{\circ} \mathrm{C}\right)$. The nucleation started on the sides of packets from a grain boundary. They were also observed at $623 \mathrm{~K}\left(350{ }^{\circ} \mathrm{C}\right)$ but it did not interfere with the study of grain boundary nucleated bainite. It seemed to have only one plate of ferrite and all were of the same variant, evidently influenced by the primary plate.

At $773 \mathrm{~K}\left(500^{\circ} \mathrm{C}\right)$, the sides of packets were covered with layers of pearlite but starting from $723 \mathrm{~K}\left(450{ }^{\circ} \mathrm{C}\right)$ the side layers consisted of a eutectoid of the same ferrite orientation as the plates and it was not possible to 
distinguish from the eutectoid colonies formed in wide interspaces. The same kind of layers was found even on single plates at $573 \mathrm{~K}$ and $548 \mathrm{~K}\left(300{ }^{\circ} \mathrm{C}\right.$ and $\left.275^{\circ} \mathrm{C}\right)$.

Starting from $723 \mathrm{~K}\left(450^{\circ} \mathrm{C}\right)$ for the $\mathrm{Fe}-\mathrm{C}$ alloy with 0.7 mass pct carbon, no change of the formation mechanism with decreasing temperature was observed for bainite nucleated on grain boundaries. The gradual occurrence of intragranular bainite, below a temperature that depends on the holding time, represents a transition in itself and, morphologically, such bainite does not start from a packet of ferrite plates but from single plates. The second stage of formation, i.e., the eutectoid reaction, for intragranular bainite occurs predominantly with the cooperative mode.

The interaction with martensite at the lower temperatures should also be mentioned. At $573 \mathrm{~K}\left(300{ }^{\circ} \mathrm{C}\right)$, the bainite units may nucleate martensite on quenching, which will cover the broad face of the bainite. The $\mathrm{M}_{\mathrm{S}}$ temperature was estimated to $539 \mathrm{~K}\left(266^{\circ} \mathrm{C}\right)$ but at 548 $\mathrm{K}\left(275^{\circ} \mathrm{C}\right)$ tempered martensite was observed with layers of bainite.

The roles of the two modes of the eutectoid transformation, degenerate and cooperative, have been further emphasized in the present report. It does not seem convenient to define the difference between upper and lower bainite with reference to their differences because their relative amounts vary gradually over a wide temperature range.

\section{ACKNOWLEDGMENTS}

The authors wish to acknowledge the financial support from VINNOVA, the Swedish Governmental Agency for Innovation Systems, Swedish industry and KTH Royal Institute of Technology. The work has been performed within the VINN Excellence Centre Hero-m. The $\mathrm{Fe}-\mathrm{C}$ alloy investigated in this work was kindly offered by Dr. I. Zuazo from Arcelor Mittal Maizieres Research (S.A.). The authors are grateful for the help from Assoc. Professor P. Hedström during the work of EBSD characterization. J. Yin would like to thank China Scholarship Council (CSC) for sponsorship of his study.

\section{OPEN ACCESS}

This article is distributed under the terms of the Creative Commons Attribution 4.0 International License (http://creativecommons.org/licenses/by/4.0/), which permits unrestricted use, distribution, and reproduction in any medium, provided you give appropriate credit to the original author(s) and the source, provide a link to the Creative Commons license, and indicate if changes were made.

\section{REFERENCES}

1. R.F. Mehl: Hardenability of Alloy Steels, Metals Park, OH, ASM, 1939, pp. 41-44
2. A. Hultgren: Trans. ASM, 1947, vol. 39, pp. 915-89.

3. H.I. Aaronson and C. Wells: Trans. AIME, 1956, vol. 206, pp. 1216-23.

4. M. Hillert: Jernkont. Ann., 1957, vol. 147, pp. 757-89.

5. T. Ko and S.A. Cottrell: J. Iron. Steel Inst., 1952, vol. 172, pp. 307-13.

6. S.J. Matas and R.F. Hehemann: Trans. AIME, 1961, vol. 221, pp. $179-85$.

7. R.H. Goodenow, S.J. Matas, and R.F. Hehemann: Trans. AIME, 1963 , vol. 227 , pp. $651-58$

8. L. Kaufman, S.V. Radcliffe, and M. Cohen: Decomposition of Austenite by Diffusional Processes, V.F. Zackay and H.I. Aaronson, eds., Interscience, New York, 1962, pp. 313-52.

9. K. Tsuya: J. Mech. Eng. Lab. Jpn., 1956, vol. 2, p. 20.

10. M. Hillert: "The Growth of Ferrite, Bainite and Martensite", Internal Report, Swedish Inst. Metal Res., Stockholm, 1960, Printed in Thermodynamics and Phase Transformations, The Selected Works of Mats Hillert, J. Ågren, Y. Bréchet, C. Hutchinson, J. Philibert, and G. Purdy, eds., EPD Sci., Les Ulis Cedex, 2006, pp. 111-58.

11. R.H. Goodenow and R.F. Hehemann: Trans. AIME, 1965, vol. 233, pp. 1777-86.

12. J.M. Oblak and R.F. Hehemann: Transformations and Hardenability in Steels, Climax Molybdenum Co., Ann Arbor, MI, 1967, pp. 15-38.

13. Y. Ohmori, H. Ohtani, and T. Kunitake: Trans. ISIJ, 1971, vol. 11 , pp. $250-59$.

14. M. Takahashi and H.K.D.H. Bhadeshia: Mater. Sci. Technol., 1990, vol. 6, pp. 592-603.

15. J. Yin, M. Hillert, and A. Borgenstam: Metall. Mater. Trans. A, 2017, vol. 48A, pp. 1425-43.

16. S.B. Singh: Phase Transformation in Steels, E. Pereloma and D.V. Edmonds, eds., Woodhead Publishing, Oxford, 2012, pp. 385-416.

17. J. Yin, M. Hillert, and A. Borgenstam: Metall. Mater. Trans. A, 2017, vol. 48A, pp. 1444-58.

18. A. Stormvinter, A. Borgenstam, and J. Ågren: Metall. Mater. Trans. A, 2012, vol. 43A, pp. 3870-79.

19. I. Gutierrez-Urrutia, S. Zaefferer, and D. Raabe: JOM, 2013, vol. 65 , pp. $1229-36$

20. S. Zaefferer and N. Elhami: Acta Mater., 2014, vol. 75, pp. 20-50.

21. Y.N. Picard, M. Liu, J. Lammatao, R. Kamaladasa, and M. De Graef: Ultramicroscopy, 2014, vol. 146, pp. 71-78.

22. H.E. Exner: Metallography and Microstructures, ASM International, Materials Park, Ohio, 2004.

23. P. Morin, M. Pitaval, D. Besnard, and G. Fontaine: Philos. Mag. A, 1979, vol. 40, pp. 511-24

24. S. Zaefferer: J. Appl. Cryst., 2000, vol. 33, pp. 10-25.

25. S. Zaefferer: Adv. Imaging Electron Phys., 2002, vol. 125, pp. 355-414.

26. M. Hillert: The Decomposition of Austenite by Diffusional Processes, V.F. Zackay and H.I Aaronson, eds., Interscience, New York, 1962, pp. 197-237.

27. H. Okamoto and M. Oka: Metall. Trans. A, 1986, vol. 17, pp. 1113-20.

28. M. Nemoto: High Voltage Electron Microscopy, P. R. Swann, C. J. Humphrey, and M. J. Goringe, eds., Academic Press, London, 1974, pp. 230-34.

29. H.K.D.H. Bhadeshia and D.V. Edmonds: Acta Metall., 1980, vol. 28, pp. 1265-73.

30. H.K.D.H. Bhadeshia: Solid-Solid Phase Transformation 1981, H. I. Aaroson, D. E. Laughlin, R. F. Sekerka, C. M. Wayman eds., TMS-AIME, Pittsburgh, 1981, pp. 1041-48.

31. P. Kolmskog, A. Borgenstam, M. Hillert, P. Hedström, S. Babu, H. Terasaki, and Y. Komizo: Metall. Mater. Trans. A, 2012, vol. $43 \mathrm{~A}$, pp. $4984-88$.

32. X.L. Wan, R. Wei, L. Cheng, M. Enomoto, and Y. Adachi: $J$. Mater. Sci., 2013, vol. 48, pp. 4345-55.

33. L. Cheng, K.M. Wu, X. L. Wan, and R. Wei: Mater. Charact., 2014, vol. 87, pp. 86-94.

34. Z.W. Hu, G. Xu, H.J. Hu, L. Wang, and Z.L. Xue: Int. J. Miner. Metall. Mater., 2014, vol. 21, pp. 371-78.

35. F.G. Caballero, M.K. Miller, and C. Garcia-Mateo: Acta Mater., 2010, vol. 58 , pp. $2338-43$

36. F.G. Caballero, M.K. Miller, C. Garcia-Mateo, J. Cornide, and M.J. Santofimia: Scripta Mater., 2012, vol. 67, pp. 846-49. 
37. F.G. Caballero, M.K. Miller, C. Garcia-Mateo, and J. Cornide: $J$. Alloys Compd., 2013, vol. 577(Suppl. 1), pp. S626-30.

38. A. Borgenstam, M. Hillert, and J. Agren: Acta Mater., 2009, vol. 57 , pp. $3242-52$

39. F.B. Pickering: Transformations and Hardenability in Steels, Climax Molybdenum Co., Ann Arbor, MI, 1967, pp. 10929.
40. M. Oka and H. Okanoto: J. Phys. IV Fr., 1995, vol. 5, pp. C8-503-08.

41. J.R. Vilella: Trans. AIME, 1940, vol. 140, pp. 332-34.

42. T.G. Nilan: Transformarion and Hardenability in Steels, Climax Molybdenum Co., Ann Arbor, MI, 1967, pp. 57-66.

43. H. Modin and S. Modin: Jernkont. Ann., 1955, vol. 39, pp. $481-515$. 